\title{
Kinetic Studies of the Homogeneous Coupling Reaction between Electrochemically Generated Aromatic Radical Anions and Alkyl Radicals
}

\author{
Steen Uttrup Pedersen, ${ }^{a, *}$ Torben Lund, ${ }^{b}$ Kim Daasbjerg, ${ }^{a}$ Mihaela Pop, ${ }^{a, c}$ \\ Ingrid Fussing ${ }^{a}$ and Henning Lund ${ }^{a}$
}

${ }^{a}$ Department of Organic Chemistry, University of Aarhus, DK-8000 Aarhus C, Denmark, ${ }^{b}$ Institute of Life Science and Chemistry, University of Roskilde, DK-4000 Roskilde, Denmark and ${ }^{\mathrm{C}}$ Romanian Academy, Institute of Organic Chemistry, Ro-71141 Bucharest, Romania

\section{Dedicated to Professor Lennart Eberson on the occasion of his 65th birthday}

Pedersen, S. U., Lund, T., Daasbjerg, K., Pop, I., Fussing, I. and Lund, H., 1998. Kinetic Studies of the Homogeneous Coupling Reaction between Electrochemically Generated Aromatic Radical Anions and Alkyl Radicals. Acta Chem. Scand. 52: 657-671. (C) Acta Chemica Scandinavica 1998.

Radicals produced via the indirect reduction of alkyl halides by aromatic radical anions are likely to couple fast with the mediator. In the presence of activated olefins or good hydrogen atom donors the fate of the alkyl radicals might be changed. In this study rate constants for the coupling reaction (2) between primary, secondary and tertiary alkyl radicals and some aromatic radical anions were measured via the competition with addition of the radical to styrene or ethyl cinnamate, or via the competition with hydrogen atom transfer from thiophenol or 2-methyl-2-propanethiol to the alkyl radical. It is shown that for all the alkyl radicals and aromatic radical anions investigated so far the rate constant for coupling is close to $1 \times 10^{9} \mathrm{M}^{-1} \mathrm{~s}^{-1}$.

All rates measured so far for the coupling reaction between radical anions of aromatic compounds and primary alkyl radicals are close to the diffusion limit. It is the aim of this investigation to examine the rate of coupling between primary, secondary and tertiary alkyl radicals and different aromatic radical anions. The interest in these coupling reactions has been reinforced recently when a new method, based on the competition between coupling and electron transfer between aromatic radical anions and alkyl radicals, allowed the highly interesting reduction potentials of alkyl radicals to be determined. Such potentials have previously been difficult to measure due to the transient lifetime of aliphatic alkyl radicals. ${ }^{1,2}$

The Aarhus group has for some time been involved in the study of the electron transfer reaction from an aromatic radical anion to alkyl halides in attempts to describe the dichotomy between electron transfer ET and $\mathrm{S}_{\mathrm{N}} 2$. The mechanism for indirect reduction of alkyl halides (RX) by aromatic mediators (A) has been described in numerous papers as eqns. (0)-(4),

\footnotetext{
* To whom correspondence should be addressed.
}

$$
\begin{aligned}
& \mathrm{A}+\mathrm{e} \rightleftharpoons \mathrm{A}^{-\cdot} \\
& \mathrm{A}^{-\cdot}+\mathrm{RX} \stackrel{k_{1}}{\longrightarrow} \mathrm{A}+\mathrm{R}^{-}+\mathrm{X}^{-} \\
& \mathrm{A}^{-\cdot}+\mathrm{R} \cdot \stackrel{k_{2}}{\longrightarrow} \mathrm{A}-\mathrm{R}^{-} \\
& \mathrm{A}^{-\cdot}+\mathrm{R}^{\cdot} \stackrel{k_{3}}{\longrightarrow} \mathrm{A}+\mathrm{R}^{-} \\
& \mathrm{R}^{-}, \mathrm{AR}^{-}+\mathrm{H}^{+} \stackrel{k_{4}}{\longrightarrow} \mathrm{RH}, \mathrm{ARH}
\end{aligned}
$$

where (1) is the rate determining dissociative ET resulting in the direct generation of an alkyl radical, $R^{\cdot 3-6}$ This radical can then react with another $\mathrm{A}^{-\cdot}$ either by coupling (2) or by further reduction (3). If $E_{\mathrm{A} / \mathrm{A}^{-}}^{\circ}$ is more positive than the reduction potential of $\mathrm{R}^{\cdot}, E_{\mathrm{R}} \cdot$, then the coupling reaction will be favoured compared with the ET reaction (3); however, if the potential of $\mathrm{A}^{-\cdot}$ becomes less than $E_{\mathrm{R}}$ then the downhill ET reaction (3) from $\mathrm{A}^{-\cdot}$ to $R^{\cdot}$ will take over. The competition between (2) and (3) determines the product and the consumption of electrons.

Attempts have been made to measure these coupling rate constants, $k_{2}$, by use of radical cyclisation probes and product analysis. Garst $e$ t al, measured rate constants 

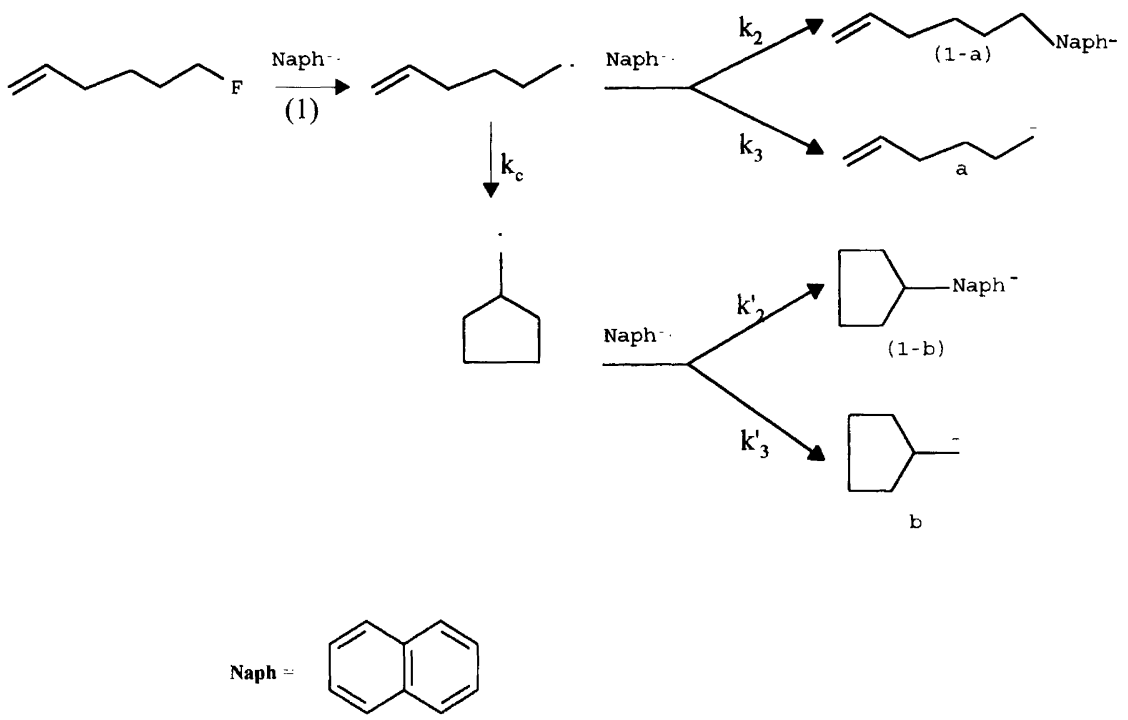

Scheme 1.

for the coupling reaction of 5-hexenyl radical and radical anions of benzophenone and naphthalene generated by sodium in dimethoxyethane. ${ }^{7-9}$ The 5 -hexenyl radical $\left(R^{*}\right)$ was formed in the indirect reduction of 5-hexenyl fluoride by the aromatic radical anion; a process that is believed to be a concerted dissociative ET in which the breakage of the $\mathrm{C}-\mathrm{F}$ bond occurs concerted with the ET reaction. This radical thus produced can either react further with another aromatic radical anion or cyclise to the cyclopentylmethyl radical $\left(\mathrm{R}^{\prime \prime}\right)$ which can subsequently react with another aromatic radical anion. The scheme presented by Garst et al. is shown in Scheme 1.

For naphthalene radical anion the overall rate constant, $k_{\text {sum }}=k_{2}+k_{3}$, was calculated from the product ratio of 1-hexene ( $\mathrm{RH}$ ) (a) and methylcyclopentane $\left(\mathrm{R}^{\prime} \mathrm{H}\right)(\mathrm{b})$, quantified by gas chromatography (GC) and from the rate constant $k_{\mathrm{c}}$ for the cyclisation of the 5 -hexenyl radical. This was possible because the competition parameters $q=k_{3} /\left(k_{2}+k_{3}\right)$ and $q^{\prime}=k_{3}^{\prime} /\left(k_{2}^{\prime}+k_{3}^{\prime}\right)$ for both radicals, $R^{\prime}$ and $R^{\prime \prime}$, respectively, were found to be the same at about 0.58 . The value found for $k_{\text {sum }}$ was $3.8 \times 10^{9} \mathrm{M}^{-1} \mathrm{~s}^{-1}$ and $k_{3} / k_{2}=1.4$ and $k_{2}$ could then easily be obtained at $1.6 \times 10^{9} \mathrm{M}^{-1} \mathrm{~s}^{-1}$. In a more recent study with benzophenone radical anion both the alkyl radicals exclusively couple with $\mathrm{A}^{-\cdot}$ to form $\mathrm{ARH}$ and AR'H because $q=q^{\prime}=0$. The coupling rate constant was found from product ratios of $\mathrm{ARH} / \mathrm{AR}^{\prime} \mathrm{H}$ and $k_{\mathrm{c}}$. The coupling rate constant was found to be $3.6 \times 10^{8} \mathrm{M}^{-1} \mathrm{~s}^{-1}$ for benzophenone when $k_{\mathrm{c}}$ was readjusted to $2.35 \times 10^{5} \mathrm{~s}^{-1} .{ }^{10}$ Similar studies were made by two of the present authors with electrochemically generated aromatic radical anions and three different radical cyclisation probes all chosen so $q=0 .{ }^{11}$ In all the previous studies, electrochemical or non-electrochemical, only primary alkyl radicals were investigated because most fast radical cyclisation probes are based on the intramolecular addition of a primary alkyl radical to an olefin.
The basic idea of introducing competition between the coupling reaction and another reaction involving the aliphatic radical is, however, still possible provided the introduced reaction is bimolecular. The simplest extension of using radical cyclisation probes is therefore a bimolecular radical addition reaction to an activated olefin. Another possibility which will be discussed later is to add a hydrogen atom donor which can transfer a hydrogen atom to the radical in competition with the coupling reaction (2).

The use of high concentrations of olefin to speed up the addition of the alkyl radical to the olefin compared with the coupling reaction, has in this paper been replaced by the use of a reproducible, low steady-state concentration of the aromatic radical anion to slow down the reaction between the latter and the alkyl radical. Both strategies favour competition of the addition reaction, but the second strategy also reduces or eliminates the problems arising from the reaction between the olefin and the aromatic radical anion. Furthermore, it will be an opportunity to show how the recently acquired reduction potentials of alkyl radicals can be used to adjust the optimal reaction conditions in terms of mediator, olefin, etc. The mechanistic scheme that will be used in the following discussion is outlined in Scheme 2. The alkyl radical $R^{\cdot}$ formed can add to the activated olefin (5) and generate a new radical that again can react with the mediator $\mathrm{A}^{-\cdot}$ by coupling (6) or electron transfer (7) depending on the potential of the radical formed compared with the standard potential of the mediator. The slow rate-determining ET reaction (1) ensures that all transient intermediates will be formed so far from the electrode surface that they will not be further reduced at the electrode.

Knowledge from numerous studies of indirect reduction of alkyl halides combined with the knowledge of the reduction potentials of alkyl radicals allow us to 


$$
\mathrm{A}+\mathrm{e}^{-}=\mathrm{A}^{-}
$$

$$
\phi+\mathrm{X}^{-}+\mathrm{R}
$$

Scheme 2.

choose reaction conditions where the general reaction scheme given above can be conveniently reduced to a few competing reactions.

In this paper two methods are presented for measurement of the coupling rate constants between aromatic radical anions and alkyl radicals by introducing competing reactions for the radical. In the first method an olefin is added to divert some of the radicals to add to the olefin instead of coupling with the aromatic radical anion, and in the second method a hydrogen atom donor is added so a hydrogen atom can be donated to the radical. Both these methods can be used in conjunction with two techniques; a direct electrochemical technique like linear sweep voltammetry (LSV), where the focus is on the change in electron consumption with the change in the reaction scheme introduced by the competing reaction, and an indirect method based on preparative methods and product analysis. The latter method, with characterisations of products and yield calculations based on the knowledge of response factors in GC from original samples, are much more tedious than the direct LSV technique. Unfortunately, the LSV technique cannot generally be used with both the methods due to constraints in establishing a fast and efficient competition, a fact which will be discussed later.

We first discuss the use of the olefin addition method. The direct technique of LSV was attempted by addition of acrylonitrile to divert alkyl radicals from coupling with fluoranthene radical anions. With the application of the indirect technique, rate constants for the coupling reaction between the anthracene radical anion and tert-, sec-, and butyl radicals were measured by the addition of styrene, and for 1,4-diacetylbenzene radical anion with the same radicals by the addition of ethyl cinnamate.

The second method, where a good hydrogen atom donor such as thiophenol or 2-methyl-2-propylthiol is added to divert the alkyl radical in the direct LSV technique, was applied to obtain the rate constant of the coupling between 1,4-dicyanobenzene radical anion and tert- and butyl and 2-propyl radicals, and between benzophenone radical anion and butyl radical. The indirect technique was not attempted in this study but will be illustrated in a forthcoming paper on the coupling of benzyl radicals with aromatic radical anions.

\section{Results and discussion}

Lorenz Walder recently described a method for discriminating between a two-electron mechanism and a oneelectron mechanism for the oxidative addition of alkyl halides to organometallic derivatives of vitamin B12.12 An activated olefin was introduced into the electrochemical cell in order to trap some of the formed alkyl radical. In cyclic voltammetry the trapped radical gave rise to a new reduction wave in the voltammogram after further coupling with the mediator. It was possible in this investigation to measure the rate of addition between 2-propyl radicals and a number of activated olefins, including acrylonitrile and acrolein, and it was found that they all had rate constants between $3 \times 10^{5} \mathrm{M}^{-1} \mathrm{~s}^{-1}$ and $5 \times 10^{6} \mathrm{M}^{-1} \mathrm{~s}^{-1}$. In these direct measurements quite high concentrations of activated olefins $(>0.1 \mathrm{M})$ were necessary, however, to trap enough of the alkyl radical. In this paper we present direct measurements that show it is not generally feasible to perform direct quantitative electrochemical measurements at such high concentrations of activated olefin with aromatic radical anions.

Possibilities for observing the competition between coupling of a radical with a radical anion and addition to an olefin by direct LSV measurement were investigated with fluoranthene, 1-iodobutane and acrylonitrile. The LSV results are shown in Fig. 1a, where the catalytic efficiency, $I_{k} / I_{\mathrm{R}}$, is plotted versus the logarithm of the scan rate, $I_{\mathrm{R}}$ is the cathodic peak current for fluoranthene alone and $I_{\mathrm{k}}$ is the peak current with 1-iodobutane present. It is observed that the catalytic efficiency, $I_{\mathrm{k}} / I_{\mathrm{R}}$, increases as expected when the concentration of acrylonitrile is increased to high levels. This is because more of the alkyl radicals are 'trapped' by the olefin and the overall electron consumption changes from two electrons per fluoranthene molecule to one or two electrons per 1 -iodobutane molecule. The latter electron number one or two depends on whether the radical formed after addition to the acrylonitrile will react further with the mediator or dimerise. Figure $1 \mathrm{~b}$ shows the same kind of plot, this time, however, without the 1 -iodobutane. It is clearly seen that the catalytic efficiency has increased even more than in Fig. 1a. We observe the indirect reduction of acrylonitrile. Quantitative treatment of the measurements presented in Fig. 1 by comparison with digitally simulated curves proved impossible owing to adsorption phenomena of polymerised acrylonitrile at the electrode.

Previous investigations have shown that many radical anions of aromatic compounds, i.e., of benzophenone and anthracene, react quite readily with activated olefins such as acrylonitrile, and initiate polymerisation, which 

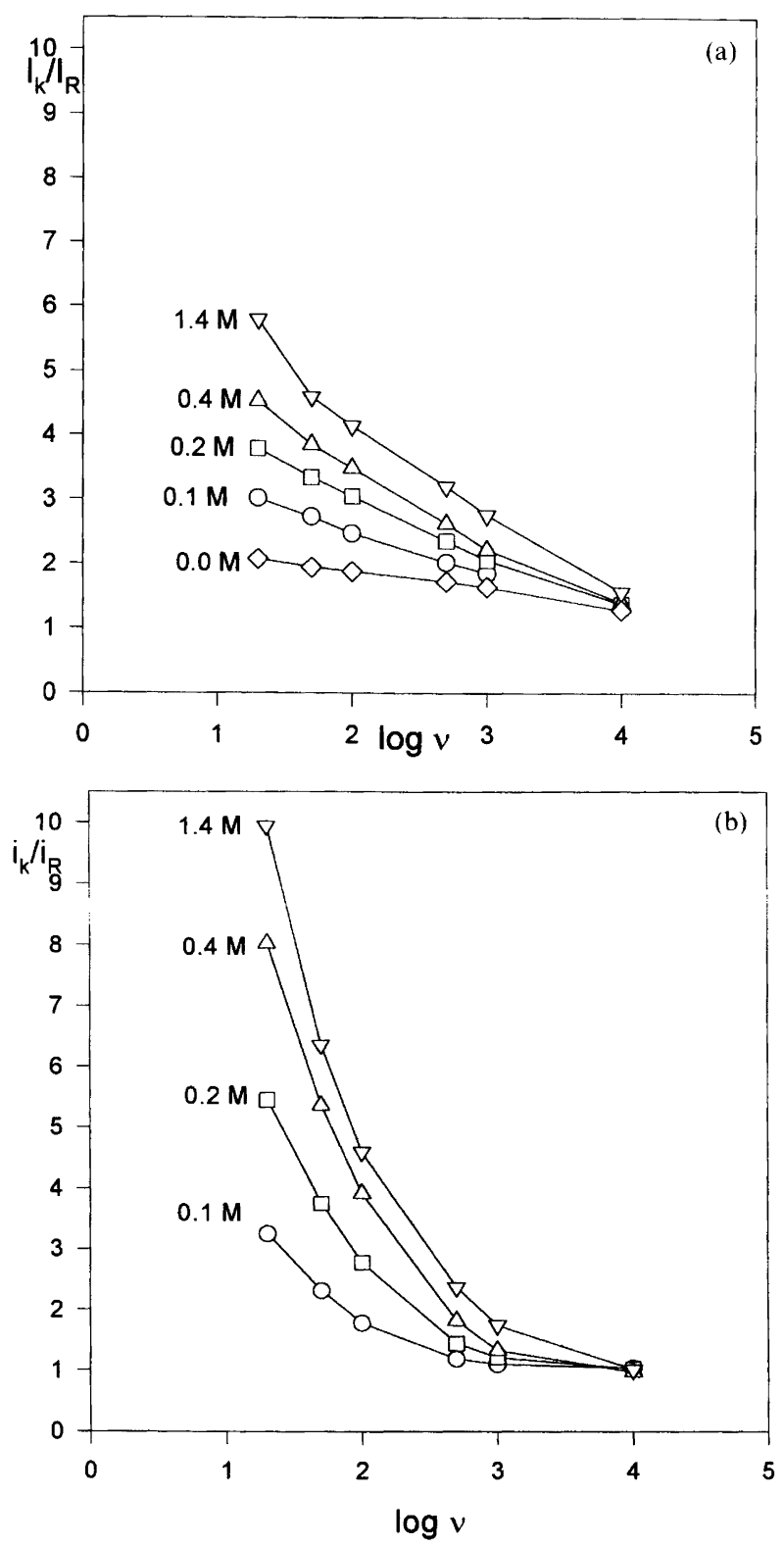

Fig. 1. Catalytic efficiency, $I_{k} / I_{R}$, versus the logarithm of the scan rate for $2 \mathrm{mM}$ fluoranthene and various concentrations of acrylonitrile in DMF-0.1 $\mathrm{M} \mathrm{Bu}_{4} \mathrm{NBF}_{4}$ at $25^{\circ} \mathrm{C}$ : (a) $10 \mathrm{mM}$ 1-iodobutane; (b) no 1-iodobutane.

causes viscosity variation and filming of the electrode; this prevents quantitative electrochemical measurements. ${ }^{13,14}$ This situation where the purely catalytic process is self-inhibited by adsorption of product on the electrode surface has recently been treated theoretically. ${ }^{15}$ The olefin radical anion will probably not be directly adsorbed onto the electrode but will initiate polymerisation, leading to oligomers and polymers which can be adsorbed. A chain reaction should therefore be included in Bhugun's reaction scheme to describe the self-inhibition in the indirect reduction of acrylonitrile. Even if this effect could be included in the reaction scheme further modifications would have to be taken into account to describe the situation with competition between coupling (2) and addition (5). This would introduce so many adjustable parameters that other strategies seem to be more attractive.

Attempts to control the polymerisation by addition of a suitable proton donor or lithium ions were not sufficiently effective to overcome these problems. The major reason for the polymerisation is the excessive concentration of acrylonitrile which is necessary for observing effects from the competition of the addition reaction in the direct electrochemical measurements. Consequently we looked for alternative ways to introduce the competition but with smaller concentrations of added olefin.

$\xi=\frac{k_{5}}{k_{2}} \cdot \frac{[\mathrm{O}]}{\left[\mathrm{A}^{-\bullet}\right]}$

The dimensionless competition parameter, $\xi$, given in eqn. (8), describes the competition between coupling (2) and addition (5) in Scheme 2 as the product of two ratios. The first ratio is between the rate constants $k_{5}$ and $k_{2}$. Unless severe steric hindrance is present in both $\mathrm{R}^{\cdot}$ and $\mathrm{A}^{-\cdot}$ the rate constant for the coupling, $k_{2}$, will be very high. Previous results for primary alkyl radicals indicate typical values of $(1-2) \times 10^{9} \mathrm{M}^{-1} \mathrm{~s}^{-1}$ for $k_{2}$, and these values will suffice as qualitative estimates, bearing in mind that determination of $k_{2}$ is the object of this study. The rate constant for the addition of alkyl radicals to activated olefins is, even in the most favourable situation, less than $2 \times 10^{6} \mathrm{M}^{-1} \mathrm{~s}^{-1}$, and therefore the ratio $k_{5} / k_{2}$ will, to a first approximation, be close to $10^{-3}$. The second ratio, which can be experimentally controlled, is between the concentrations $[\mathrm{O}]$ and $\left[\mathrm{A}^{-\cdot}\right]$, where $O$ is the activated olefin and $A^{-\cdot}$ the aromatic mediator. In a direct LSV experiment $[\mathrm{A}]$ is $1-2 \mathrm{mM}$ and the rate-determining ET reaction between $\mathrm{A}^{-\cdot}$ and RX should be quite fast before a distinct catalytic effect is observed in the voltammogram. This means, however, that $\mathrm{A}^{-\cdot}$ and $\mathrm{R}^{\cdot}$ exist only in a thin reaction layer close to the electrode where all reactions involving $\mathrm{A}^{-\cdot}$ take place, including the coupling reaction (2). The average concentration of $\mathrm{A}^{-\cdot}$ in the reaction layer, that is much thinner than the diffusion layer, can be found by digital simulation and is approximately $10 \%$ of $[\mathrm{A}]_{\text {bulk }}$. A molar concentration of the olefin $(>0.1 \mathrm{M})$ is therefore necessary for the competition to be effective in LSV, $\xi \approx 1$, keeping in mind the approximate value of $10^{-3}$ for $k_{5} / k_{2}$.

This competition between (2) and (5) can, however, also be accentuated by decreasing the concentration of $\mathrm{A}^{-\cdot}$ in the reaction layer; this strategy is followed in this investigation.

When the rate-determining reaction (1) is slow, the reaction will no longer be confined to the thin layer adjacent to the electrode and no catalytic effect will be seen in CV or LSV. The ET reaction will instead take place in the bulk of the cell and the kinetics might be monitored by a number of methods including in situ UV-VIS spectroscopy. Steady-state conditions will develop for $\mathrm{A}^{-\cdot}$ when the electrochemical rate of forma- 
tion of $\mathrm{A}^{-\cdot}$ is equal to the consumption by the initial ET reaction between the mediator, $A^{-\cdot}$, and the alkyl halide (1). The electrochemical rate of formation is directly controlled by the current delivered by the galvanostat as shown in eqn. (9), and the rate of consumption of the mediator given in eqn. (10) is controlled by the rate-determining ET reaction (1). The factor 2 is included for stoichiometric reasons, which we shall return to below. The steady-state concentration of $\mathrm{A}^{-},\left[\mathrm{A}^{-}\right]_{\mathrm{ss}}$, can, through a combination of eqns. (9) and (10), be expressed by eqn. (11), where $F$ is the Faraday constant, $V$ the volume of the cell and $i$ the galvanostatic current.

$\left(\partial\left[\mathrm{A}^{-\cdot}\right] / \partial t\right)_{\text {formation }}=\frac{-i}{F V}$

$\left(\partial\left[\mathrm{A}^{-\cdot}\right] / \partial t\right)_{\text {consumption }}=-2 k_{1}\left[\mathrm{~A}^{-\cdot}\right][\mathrm{RX}]$

$\left[\mathrm{A}^{-\cdot}\right]_{\mathrm{ss}}=\frac{-i}{2 F V k_{1}[\mathrm{RX}]}$

$\left[\mathrm{A}^{-\cdot}\right]_{\mathrm{ss}}$ can therefore be kept constant under galvanostatic conditions when the concentration of $\mathrm{RX}$ is constant, a situation which is obtained under pseudo-firstorder conditions, i.e., $[\mathrm{RX}]>10[\mathrm{~A}]$. The competition parameter, $\xi$, will then be constant during the experiment and equal to the product ratio obtained, [ORH]/[ARH], shown in eqn. (12), where ORH is the addition product of $R^{\prime}$ to the olefin, $\mathrm{O}$.

$\xi=\frac{[\mathrm{ORH}]}{[\mathrm{ARH}]}=\frac{2 F V k_{1} k_{5}[\mathrm{O}][\mathrm{RX}]}{-i k_{2}}$

A factor of two was included in eqn. (10) for stoichiometric reasons. Without the competition from addition to the olefin, two molecules of $\mathrm{A}^{-\cdot}$ are consumed when one molecule of RX reacts because the reactions (2) and (3) are much faster than the rate-determining step (1). When the olefin is added this stoichiometry could be changed from 2 to 1 if the radical formed, OR', does not react with $\mathrm{A}^{-}$. Other kinds of reaction that could change the overall number of electrons consumed are dimerisation of the radicals, polymerisation ending in stable radicals or hydrogen atom abstraction from the solvent if the radical formed does not react further with a molecule of $\mathrm{A}^{-\cdot}$.

Aliphatic alkyl radicals are known to add regioselectively to ethyl cinnamate and styrene to form the benzylic radicals, denoted OR', as the only product. ${ }^{16,17}$ In Fig. 2 the range of reduction potentials for benzylic radicals is shown relative to the reduction potentials of alkyl radicals and the thiophenoxide radical. The latter radical is interesting in the application of the second method because it is formed by hydrogen atom abstraction from the hydrogen donor thiophenol.

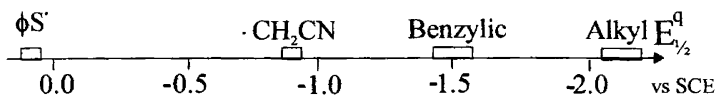

Fig. 2. Reduction potentials $E_{q / 2}^{q}$ for alkyl and benzylic radicals vs. SCE in DMF as measured in Ref. 1.
The mediator used in this project should have a standard potential higher than the reduction potentials of the alkyl radicals to prevent further reduction of the radical. This means that only mediators with $E_{\mathbf{A} / \mathbf{A}^{-}}^{\circ}$. higher than $-2.1 \mathrm{~V}$ vs. SCE can be considered, and under such conditions the alkyl radical will not be reduced; it will only couple with the aromatic radical anion. The benzylic radical, OR', formed after the addition of the alkyl radical to the styrene or ethyl cinnamate, can either react with the aromatic radical anion by coupling or reduction or it can react with the olefin resulting in oligomers. However, because benzylic radicals are known to add to olefins much more slowly than do aliphatic radicals, i.e., tert-butyl radical adds to styrene at least 100 times faster than a benzyl radical, ${ }^{18,19}$ and because the competition between (2) and (5) is not completely in favour of (5), it follows that the further addition of $\mathrm{OR}^{*}$ to the olefin cannot compete with the reaction with the aromatic radical anion. The latter competition, coupling or further reduction of the benzylic radical, will depend on the value of $E_{\mathbf{A} / \mathbf{A}^{-}}^{\circ}$. relative to the reduction potential of the benzylic radical. If only mediators with $E_{\mathrm{A} / \mathrm{A}^{-}}^{\circ}$ lower than $-1.45 \mathrm{~V}$ vs. SCE are considered then the reduction (7) will be much faster than the coupling (6). Indeed (7) is then an ET reaction with $\Delta G^{\circ} \ll 0$ and the reaction will be diffusion controlled $\left(k_{7} \approx 10^{10} \mathrm{M}^{-1} \mathrm{~s}^{-1}\right)$. Dimerisation of radicals can be neglected since the steady-state concentrations of both $R$. and $\mathrm{OR}^{\prime}$ are very small, due to the slow rate-determining step that controls their rate of formation and their fast follow-up reactions. Hydrogen atom transfer to benzylictype radicals is also quite slow; about 1000 times slower than for aliphatic alkyl radicals and, therefore, if the alkyl radical, as found in previous studies, does not abstract a hydrogen atom from the solvent or supporting electrolyte, then this is also a highly unlikely process for benzylic-type radicals. We can therefore expect that the stoichiometry in $\mathrm{A}^{-\cdot}$ will be 2 with or without styrene/ethyl cinnamate present as long as only mediators with standard potentials between $-2.10 \mathrm{~V}$ and $-1.45 \mathrm{~V}$ vs. SCE are used; the competition will then be between coupling with the aromatic radical anion (2) and addition to the olefin, followed by fast reduction of the benzylic radical by $\mathrm{A}^{-\cdot}$.

The steady-state concentration of $\mathbf{A}^{-\cdot},\left[\mathrm{A}^{-\cdot}\right]_{\mathrm{ss}}$, can either be calculated from eqn. (11) or measured by UV-VIS spectroscopy using a fibre-optic spectrometer and a dip-in probe immersed directly into the cathodic compartment during the electrolysis. $\lambda_{\max }$ was measured for the blue radical anions of anthracene and $p$ diacetylbenzene and was $731 \mathrm{~nm}$ and $621 \mathrm{~nm}$, respectively. In Fig. 3 experimental tracking of the absorption of anthracene radical anion at $731 \mathrm{~nm}$ vs. time is shown under the various conditions described below. This led to measurements of the extinction coefficient of anthracene radical anion, of $k_{1}$ for reaction with sec-butyl chloride and finally to a measurement of the steady-state 


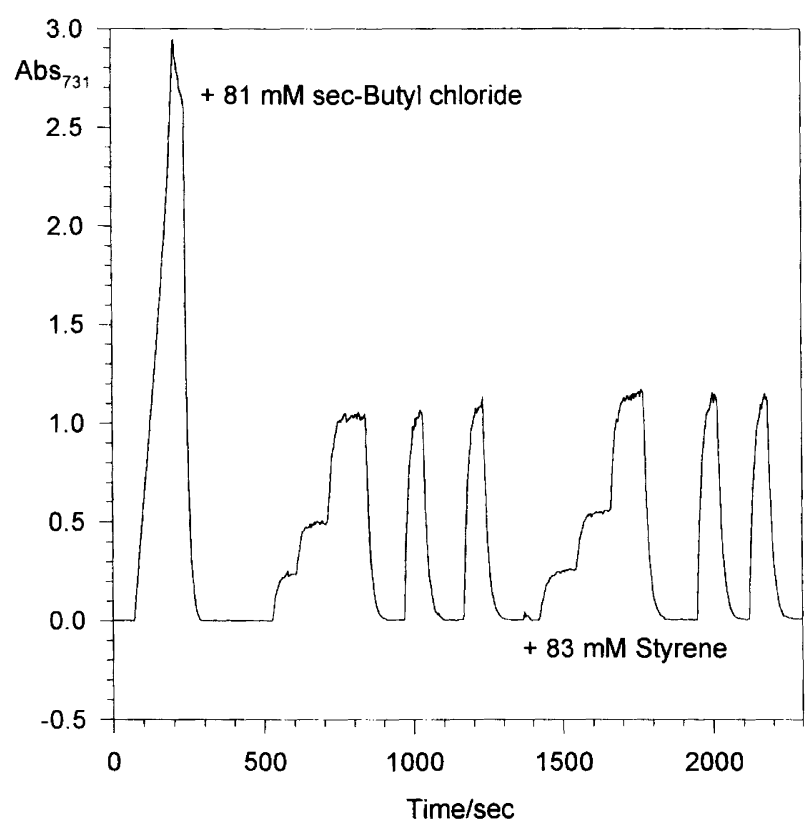

Fig. 3. Absorption at $731 \mathrm{~nm}$ vs. time measured with a dip-in probe inserted into the cathodic compartment of an $\mathrm{H}$-cell initially containing $2 \mathrm{mM}$ of anthracene in $25 \mathrm{ml} \mathrm{DMF}-0.1 \mathrm{M}$ $\mathrm{Bu}_{4} \mathrm{NBF}_{4}$ at $25^{\circ} \mathrm{C}$.

concentration of $\mathrm{A}^{-\cdot}$ in the presence of sec-butyl chloride, with and without styrene present.

During the experiment the absorption at $731 \mathrm{~nm}$ was continuously measured every second. The reference for the absorbance measurement was recorded with the dip-in probe in the cathodic solution containing anthracene and supporting electrolyte. After approximately one minute the galvanostatic current of $5 \mathrm{~mA}$ was switched on and a blue colouration appeared in the cathodic compartment. The absorption (Fig. 4) increased linearly with time. The slope $\alpha$ was found by regression analysis to be 0.01839 with a correlation coefficient of 0.9996 .

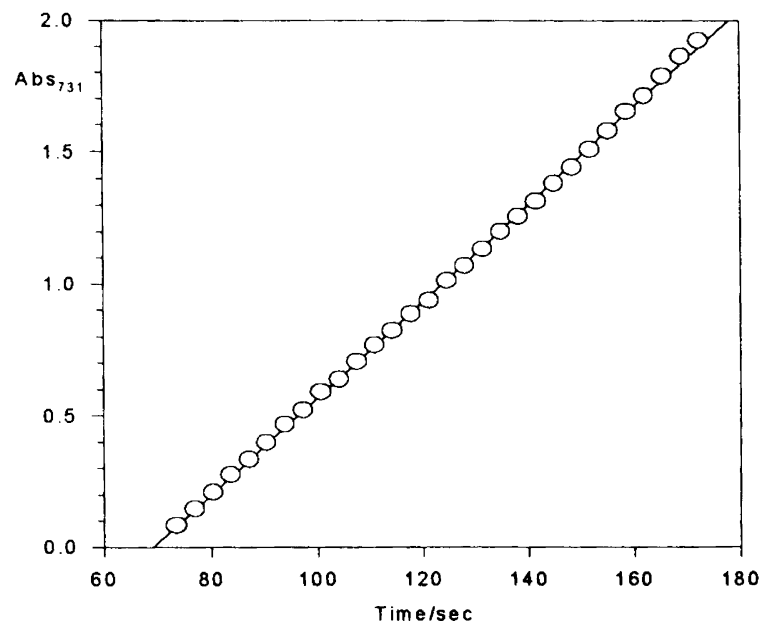

Fig. 4. Absorption at $731 \mathrm{~nm}$ vs. time (same condition as given for Fig. 3) for the time interval 70-180 s where the anthracene was reduced galvanostatically at $5 \mathrm{~mA}$. The best straight line is included in the plot.
Table 1. Absorption maxima and extinction coefficients for aromatic radical anions, $A^{-}$, in DMF- $0.1 \mathrm{M} \mathrm{Bu}_{4} \mathrm{NBF}_{4}$.

\begin{tabular}{lll}
\hline Aromatic hydrocarbon & $\lambda_{\max } / \mathrm{nm}$ & $\log \varepsilon$ \\
\hline Anthracene & 731 & $4.01( \pm 0.04)$ \\
$p$-Diacetylbenzene & 621 & $4.17( \pm 0.04)$ \\
\hline
\end{tabular}

From the slope we were immediately able to determine the extinction coefficient, $\varepsilon$, via eqn. (13).

$\varepsilon=\frac{\alpha F V l}{|i|}$

The measured values of $\lambda_{\max }$ and $\varepsilon$ for anthracene and $p$-diacetylbenzene are given in Table 1. Detailed UV-VIS spectra and diffusion coefficients for a number of aromatic radical anions, including anthracene and $p$ diacetylbenzene, have recently been measured by this new method and a manuscript is in preparation. After approximately $180 \mathrm{~s}$ the galvanostatic current was switched off and the alkyl halide, in this case sec-butyl chloride, was added to the now strongly coloured cathodic solution; the colour disappeared rapidly. After $500 \mathrm{~s}$ a current of $5 \mathrm{~mA}$ was again applied and a steady-state colouration slowly evolved. $\left[\mathrm{A}^{-}\right]_{\mathrm{ss}}$ could then be measured. The current was then changed to $10 \mathrm{~mA}$ and finally to $20 \mathrm{~mA}$, each time $\left[\mathrm{A}^{-\cdot}\right]_{\mathrm{ss}}$ being measured. The steadystate concentrations of $\mathrm{A}^{-}$given in Table 4 were calculated from the steady-state absorption found at 5.0, 10 and $20 \mathrm{~mA}$ electrolysis current.

The current was switched off after approximately $800 \mathrm{~s}$ and an exponential pseudo-first-order decay was observed. This measurement was repeated three times in the time interval $800-1300 \mathrm{~s}$. A plot of the natural logarithm of the absorption at $731 \mathrm{~nm}$ vs. the time is shown in Fig. 5. The slope obtained from the regression analysis gives the pseudo-first-order rate constant $k_{1}^{\prime}$ for the ET-reaction between anthracene radical anion and $s e c$-butyl chloride. The rate constant $k_{1}$ is easily obtained from eqn. (14). The rate constants $k_{1}$ for anthracene and the three butyl chlorides are given in Table 2. Similar experiments were carried out with $p$-diacetylbenzene and the three butyl bromides and the results are included in Table 3.

$k_{1}=\frac{k_{1}^{\prime}}{2[\mathrm{RX}]}$

In both cases the rate constants, $k_{1}$, for the dissociative electron transfer reaction for anthracene and $p$ diacetylbenzene were found to be higher for tertiary alkyl halides than for primary alkyl halides. The same trend has been observed for many other mediators in previous studies and stems primarily from electronic effects on the alkyl radical formed. ${ }^{6,20}$ Tertiary alkyl radicals are expected to be more stable than primary alkyl radicals and subsequently the bond-dissociation energy of the $\mathrm{C}-\mathrm{X}$ bond in butyl halides is smaller for tert-butyl halides than for butyl halides. The standard potential, $E^{\circ}$, for 


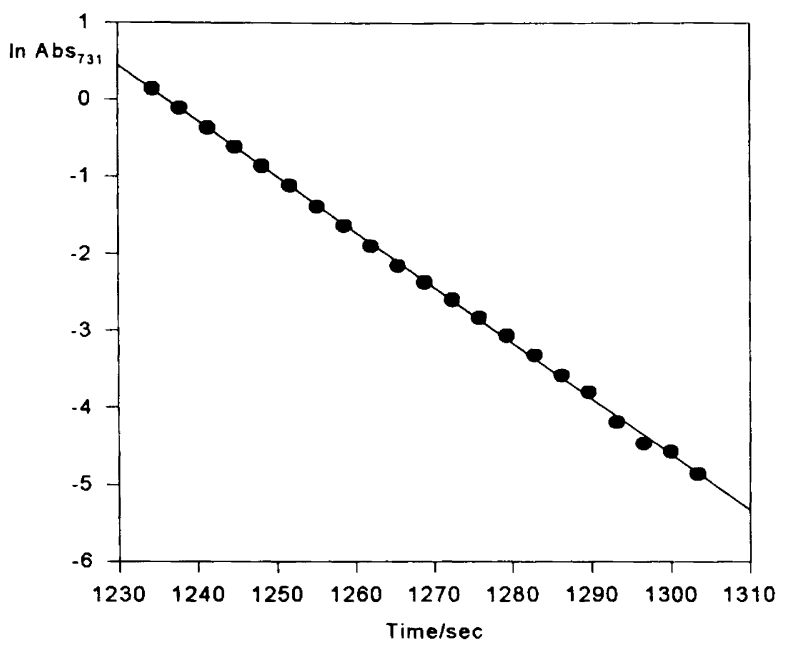

Fig. 5. Natural logarithm of absorption at $731 \mathrm{~nm}$ vs. time (same conditions as given for Fig. 3 ) for the time interval $1230-1310 \mathrm{~s}$ where the generated anthracene radical anion $(\approx 0.1 \mathrm{mM})$ undergoes a pseudo-first-order reaction with secbutyl chloride $(\approx 81 \mathrm{mM})$. The best straight line is included in the plot.

Table 2. Rate constants for electron transfer from electrochemically generated anthracene radical anion to some butyl chlorides in DMF-0.1 M Bu $\mathrm{NBF}_{4}$ at $25^{\circ} \mathrm{C}$.

\begin{tabular}{llll}
\hline & $\begin{array}{l}\text { Butyl } \\
\text { chloride }\end{array}$ & $\begin{array}{l}\text { sec-Butyl } \\
\text { chloride }\end{array}$ & $\begin{array}{l}\text { tert-Butyl } \\
\text { chloride }\end{array}$ \\
\hline$k_{1} / \mathrm{M}^{-1} \mathrm{~s}^{-1}$ & 0.16 & 0.43 & 0.70 \\
\hline
\end{tabular}

alkyl halides when defined as $\mathrm{RX} / \mathrm{R}^{\cdot}+\mathrm{X}^{-}$, reflects this difference in bond-dissociation energy, and the standard potentials for tert-butyl halides are therefore less negative than the corresponding standard potentials for butyl halides. This results in higher ET-rates for tert-butyl halides than for butyl halides from the same electron donor. $\mathrm{S}_{\mathbf{N}} 2$-character or inner-sphere ET components in eqn. (1) have been the subject of discussions for quite a long time. Several results from careful product distribution analyses of coupling reactions between anthracene radical anions and different alkyl halides have shown that up to $50 \%$ of the coupling products, alkyldihydroanthracenes, might in fact be formed in a direct $\mathrm{S}_{\mathrm{N}} 2$ reaction when the alkyl chloride is primary, whereas secondary and tertiary alkyl halides are found not to participate in $\mathrm{S}_{\mathrm{N}}$ 2-reactions to an appreciable extent. ${ }^{21}$ The possible involvement of the direct $S_{N} 2$ reaction with primary alkyl halides would increase the yield of coupling product with the aromatic radical anion relative to other

Table 3. Rate constants for electron transfer from electrochemically generated $p$-diacetylbenzene radical anion to some butyl bromides in DMF-0.1 M Bu $\mathrm{NBF}_{4}$ at $25^{\circ} \mathrm{C}$.

\begin{tabular}{llll}
\hline & $\begin{array}{l}\text { Butyl } \\
\text { bromide }\end{array}$ & $\begin{array}{l}\text { sec-Butyl } \\
\text { bromide }\end{array}$ & $\begin{array}{l}\text { tert-Butyl } \\
\text { bromide }\end{array}$ \\
\hline$k_{1} / \mathrm{M}^{-1} \mathrm{~s}^{-1}$ & 0.10 & 0.34 & 0.33 \\
\hline
\end{tabular}

products formed by trapping the alkyl radical, the consequence being that estimation of $k_{2}$ from the competition experiments leads to values of $k_{2}$ that are too high in the case of primary alkyl halides, but generally the factor will be less than two.

After approximately $1400 \mathrm{~s}$, under the conditions given in Fig. 3, styrene ( $83 \mathrm{mM})$ was added to the solution and again $\left[\mathrm{A}^{-\cdot}\right]_{\mathrm{ss}}$ was recorded at electrolysis currents equal to $5 \mathrm{~mA}, 10 \mathrm{~mA}$ and $20 \mathrm{~mA}$. The addition of the styrene does not decrease the steady-state concentration of $\mathrm{A}^{-}$. In fact a small increase of approximately $6 \%$ in $\left[\mathrm{A}^{-\cdot}\right]_{\mathrm{ss}}$ can be seen.

From 1750-2300 s, again three pseudo-first-order decay experiments were performed and in all cases it was found that the rate constant $k_{1}$ and $\left[\mathrm{A}^{-\cdot}\right]_{\mathrm{ss}}$ are the same with or without the styrene present, which is in accordance with expectations based on reaction Scheme 2. If the addition of the olefin had changed the electron stoichiometry from 2 to 1 , it would be expected that $\left[\mathrm{A}^{-\cdot}\right]_{\mathrm{ss}}$ would double and the pseudo-first-order rate constants $k^{\prime}$ would be halved. Neither of these changes is observed and therefore the stoichiometry before and after the addition of the olefin is maintained at 2 .

In Tables 4 and 5 values for $\left[\mathrm{A}^{-\cdot}\right]_{\mathrm{ss}}$ measured by UV spectroscopy are compared with $\left[\mathrm{A}^{-\cdot}\right]_{\mathrm{ss}}$ values calculated from eqn. (11) for anthracene and $p$-diacetylbenzene, respectively. The correlation between calculated and measured $\left[\mathrm{A}^{-}\right]_{\mathrm{ss}}$ is excellent, especially when the low level of concentration measured from $16-242 \mu \mathrm{M}$ is considered. The differences in $\left[\mathrm{A}^{-\cdot}\right]_{\mathrm{ss}}$ are generally within $20 \%$ which is smaller than the uncertainty expected for the product ratios $[\mathrm{ORH}] /[\mathrm{ARH}]$.

Unfortunately, only a few absolute rate constants for the addition of alkyl radicals to olefins can be found in the literature. Most studies of radical additions focus on the effects of structural changes in the radical or the olefin and for this purpose relative rate constants are adequate and much easier to obtain experimentally. The rate constants, $k_{5}$, for the addition of the different aliphatic alkyl radicals to styrene and ethyl cinnamate were sought but only the absolute rate constant $k_{5}$ for addition of tert-butyl radical to styrene in propanol was found; this value was measured by Münger and Fischer by time-resolved EPR spectroscopy to be $1.32 \times 10^{5} \mathrm{M}^{-1} \mathrm{~s}^{-1} .{ }^{19}$ The addition rate constants of radicals to olefins are normally considered to be rather insensitive to specific solvent effects, and therefore the rate constant is assumed to be the same in DMF as in propanol. $k_{5}$ values for the addition of sec-butyl and butyl radicals to styrene were extracted by combining relative and absolute rate constants from Tables 3 and 4 of Ref. 19. $k_{5}$ for the butyl radical was estimated as the average of the rate constants for addition of the methyl radical and the addition of the cyclohexyl radical. The sec-butyl radical is assumed to add to styrene with the same rate constant as the cyclohexyl radical.

Holm et al. found, from product studies, that tertbutyl radicals add about twice as fast to ethyl cinnamate 
Table 4. Measured and calculated steady-state concentrations for anthracene radical anion, $\left[\mathrm{A}^{-\cdot}\right]_{\mathrm{ss}}$, in the presence of alkyl chlorides during constant current electrolysis in DMF-0.1 M Bu $\mathrm{NBF}_{4}$ at $25^{\circ} \mathrm{C}$.

\begin{tabular}{|c|c|c|c|c|c|c|}
\hline $\mathrm{R}=\mathrm{Alkyl}$ & $-i / \mathrm{mA}$ & $V / I$ & {$[\mathrm{RBr}] / \mathrm{M}$} & $k_{1} / \mathrm{M}^{-1} \mathrm{~s}^{-1}$ & $10^{5}\left[\mathrm{~A}^{-\cdot}\right] / \mathrm{M}$ measured ${ }^{a}$ & $10^{5}\left[\mathrm{~A}^{-\cdot}\right] / \mathrm{M}$ calculated ${ }^{b}$ \\
\hline Butyl & 4.66 & 0.031 & 0.0772 & 0.16 & 5.0 & 6.3 \\
\hline Butyl & 9.96 & 0.031 & 0.0772 & 0.16 & 9.7 & 13.5 \\
\hline Butyl & 20.0 & 0.031 & 0.0772 & 0.16 & 24.2 & 27.0 \\
\hline sec-Butyl & 5.0 & 0.029 & 0.0813 & 0.43 & 2.5 & 2.6 \\
\hline sec-Butyl & 10.0 & 0.029 & 0.0813 & 0.43 & 5.4 & 5.1 \\
\hline sec-Butyl & 20.0 & 0.029 & 0.0813 & 0.43 & 11.3 & 10.2 \\
\hline tert-Butyl & 5.0 & 0.033 & 0.0797 & 0.7 & 1.6 & 1.4 \\
\hline tert-Butyl & 10.0 & 0.033 & 0.0797 & 0.7 & 3.1 & 2.8 \\
\hline tert-Butyl & 20.0 & 0.033 & 0.0797 & 0.7 & 6.9 & 5.6 \\
\hline
\end{tabular}

${ }^{a}$ Steady-state concentration of anthracene radical anion measured spectrophotometrically at $731 \mathrm{~nm}$, log $\varepsilon=4.01 .{ }^{b} \mathrm{Calculated}$ from eqn. (11).

Table 5. Measured and calculated steady-state concentrations for $p$-diacetylbenzene radical anion [A $\left.{ }^{-\cdot}\right]_{s s}$ in the presence of alkyl bromides during constant current electrolysis in DMF- $0.1 \mathrm{M} \mathrm{Bu}_{4} \mathrm{NBF}_{4}$ at $25^{\circ} \mathrm{C}$.

\begin{tabular}{|c|c|c|c|c|c|c|}
\hline Alkyl bromides & $i / \mathrm{mA}$ & $V / 1$ & {$[\mathrm{RBr}] / \mathrm{M}$} & $k_{1} / \mathrm{M}^{-1} \mathrm{~s}^{-1}$ & $10^{5}\left[\mathrm{~A}^{-\cdot}\right] / \mathrm{M}$ measured ${ }^{a}$ & $10^{5}\left[\mathrm{~A}^{-\cdot}\right] / \mathrm{M}$ calculated ${ }^{b}$ \\
\hline Butyl & 5.02 & 0.030 & 0.078 & 0.10 & 13.5 & 11.1 \\
\hline Butyl & 5.02 & 0.030 & 0.155 & 0.10 & 7.2 & 5.6 \\
\hline Butyl & 5.02 & 0.030 & 0.310 & 0.10 & 3.3 & 2.8 \\
\hline sec-Butyl & 5.03 & 0.031 & 0.074 & 0.34 & 3.1 & 3.3 \\
\hline sec-Butyl & 8.80 & 0.031 & 0.074 & 0.34 & 6.1 & 5.8 \\
\hline sec-Butyl & 19.5 & 0.031 & 0.074 & 0.34 & 14.0 & 13.0 \\
\hline tert-Butyl & 5.0 & 0.033 & 0.079 & 0.33 & 3.2 & 3.0 \\
\hline tert-Butyl & 10.0 & 0.033 & 0.079 & 0.33 & 7.0 & 6.0 \\
\hline tert-Butyl & 20.0 & 0.033 & 0.079 & 0.33 & 13.3 & 12.1 \\
\hline
\end{tabular}

${ }^{a}$ Steady-state concentration of $p$-diacetylbenzene radical anion measured spectrophotometrically at $621 \mathrm{~nm}, \mathrm{log} \varepsilon=4.17$.

${ }^{b}$ Calculated from eqn. (11).

as to $\alpha$-methylstyrene in diethylether. ${ }^{17}$ It seems reasonable, when compared with studies of $\alpha$-effects of a methyl substituent on rates of additions to acryl ester and from steric and electronic considerations, that $k_{5}$ for tert-butyl addition to $\alpha$-methylstyrene is approximately the same as to styrene. ${ }^{22} k_{5}$ for the addition of tert-butyl radicals to ethyl cinnamate is therefore assumed to be twice that for addition to styrene and so are the $k_{5}$ values used for the addition of the other butyl radicals to ethyl cinnamate. Rate constants, $k_{5}$, for the addition of butyl radicals to styrene and ethyl cinnamate used below are collected in Table 6.

Table 6. Rate constants, $k_{5} / \mathrm{M}^{-1} \mathrm{~s}^{-1}$, for the addition of alkyl radicals to olefins at $300 \mathrm{~K}$ in 2-propanol. ${ }^{a}$

\begin{tabular}{|c|c|c|c|c|}
\hline \multirow[b]{2}{*}{ Olefin } & \multicolumn{4}{|l|}{ Radical } \\
\hline & $\cdot \mathrm{CH}_{3}$ & $\cdot \mathrm{CH}_{2} \mathrm{CH}_{3}$ & $c-\mathrm{C}_{6} \mathrm{H}_{11}$ & $\cdot \mathrm{C}\left(\mathrm{CH}_{3}\right)_{3}$ \\
\hline Ethene & 840 & 730 & 625 & 2630 \\
\hline Styrene & $1.9 \times 10^{4}$ & $3.1 \times 10^{4} c$ & $4.2 \times 10^{4}$ & $1.32 \times 10^{5}$ \\
\hline $\begin{array}{l}\text { Ethyl- } \\
\text { cinnamate }\end{array}$ & $3.8 \times 10^{4}$ & $6.2 \times 10^{4}$ & $8.4 \times 10^{4}$ & $2.6 \times 10^{5}$ \\
\hline
\end{tabular}

${ }^{a}$ Calculated from Arrhenius parameters for addition to ethylene and relative rate constants. ${ }^{19} b$ tert-Butyl radicals add to ethyl cinnamate twice as fast as to $\alpha$-methylstyrene according to $\mathrm{Holm}$ et al. ${ }^{17}{ }^{c}$ Calculated as the average between $\mathrm{CH}_{3}$ and $c-\mathrm{C}_{6} \mathrm{H}_{11}$.
Table 7. Coupling product distribution between position 9, 2 and 1 found by GC analysis of preparative electrolysis of anthracene and butyl chlorides.

\begin{tabular}{llll}
\hline Butyl (R) & $\%$ 9-R-AH & $\%$ 2-R-AH & \% 1-R-AH \\
\hline Butyl & 71 & 17 & 12 \\
sec-Butyl & 62 & 20 & 18 \\
tert-Butyl & 51 & 29 & 20 \\
\hline
\end{tabular}

The determination of the product ratio [ORH]/[ARH] by gas chromatography is complicated, in the case of anthracene, by the formation of coupling products in the 1, 2 and 9 positions. The GC product analysis showed a high degree of reproducibility of distribution of coupling products. In Table 7 the average product ratios from three experiments are given. The deviations from these average product ratios were less than $5 \%$ and typically $2 \%$. The numbers are also in accordance with those reported in Ref. 21.

Aliphatic alkyl radicals are known to add regioselectively to ethyl cinnamate and styrene to form benzylic radicals, OR', which add too slowly to another olefin molecule to compete with the fast ET reaction with the mediator. The anion formed, $\mathrm{OR}^{-}$, will probably be protonated by the supporting electrolyte. The latter will then undergo Hofmann degradation to tributylamine and 1-butene; the 1-butene will escape with 
the nitrogen flush. ORH and tributylamine are both observed by GC-MS. No oligomers were detected in GC-MS. The anionic addition product, $\mathrm{OR}^{-}$, could react with another $\mathrm{RX}$ in a normal $\mathrm{S}_{\mathrm{N}} 2$ reaction but the product, ORR, was never detected by GC-MS.

The coupling rate constants, $k_{2}$, can now be obtained from eqn. (12). $\left[\mathrm{A}^{-\cdot}\right]_{s s}$ is calculated from the current, [RX] and $k_{1}$ using eqn. (11). The experimental results for anthracene/butyl chlorides/styrene and $p$-diacetylbenzene/butyl bromides/ethyl cinnamate are given in Tables 8 and 9 , respectively.

The $k_{2}$ values were obtained by combining the data in Tables 6,8 and 9 and are given in Table 10. It is seen that the anthracene radical anion couples with tert-, secand butyl radicals with the same rate constant: about $9 \times 10^{8} \mathrm{M}^{-1} \mathrm{~s}^{-1} \cdot p$-Diacetylbenzene radical anions also react with the three different radicals with the same rate constant but here the value is slightly larger, about $1.5 \times 10^{9} \mathrm{M}^{-1} \mathrm{~s}^{-1}$. Note that the rate constants $k_{2}$ for the primary alkyl radicals should be considered as max-
Table 10. Coupling rate constants, $k_{2}$, for the reaction between anthracene and $p$-diacetylbenzene radical anions and butyl radicals in DMF- $0.1 \mathrm{M} \mathrm{Bu}_{4} \mathrm{NBF}_{4}$ at $25^{\circ} \mathrm{C}$.

\begin{tabular}{lllll}
\hline Mediator (A) & Radical (R) & $10^{4} k_{2} / k_{5}$ & $\begin{array}{c}10^{-4} k_{5} / \\
\mathrm{M}^{-1} \mathrm{~s}^{-1}\end{array}$ & $\begin{array}{c}10^{-9} k_{2} / \\
\mathrm{M}^{-1} \mathrm{~s}^{-1}\end{array}$ \\
\hline Anthracene & tert-Butyl & $0.6(1)$ & 13.8 & 0.8 \\
$\begin{array}{c}\text { Anthracene } \\
\text { Anthracene }\end{array}$ & sec-Butyl & $2.3(6)$ & 4.2 & 1.0 \\
$\begin{array}{c}p \text {-Diacetyl } \\
\text { benzene }\end{array}$ & tert-Butyl & $0.6(1)$ & 28 & 1.7 \\
$\begin{array}{c}p \text {-Diacetyl } \\
\text { benzene }\end{array}$ & sec-Butyl & $1.6(3)$ & 8.4 & 1.3 \\
$\begin{array}{c}p \text {-Diacetyl } \\
\text { benzene }\end{array}$ & Butyl & $3(1)$ & 6.2 & 2 \\
\hline
\end{tabular}

imum values due to the possible influence from a competing $S_{N} 2$ reaction between $A^{-\cdot}$ and $R X .^{21}$

The alkyl radical can also be diverted by hydrogen atom addition from a good hydrogen atom donor. Franz and Alnajjar have studied the reaction between alkyl

Table 8. Rate constant ratios $k_{2} / k_{5}$ for reaction between anthracene radical anion and alkyl chlorides in the presence of styrene (O) from product ratio, $[\mathrm{ORH}] /[\mathrm{ARH}]$ between addition product to styrene $(\mathrm{ORH})$ and aromatic coupling products (ARH). The number of electrons $n$ is calculated with respect to [A].

\begin{tabular}{|c|c|c|c|c|c|c|c|c|c|}
\hline Alkyl chloride & $-i / \mathrm{mA}$ & {$[\mathrm{A}] / \mathrm{mM}$} & {$[\mathrm{RX}] / \mathrm{mM}$} & {$[0] / \mathrm{mM}$} & $\mathrm{V} / \mathrm{ml}$ & $n$ & $10^{5}\left[\mathrm{~A}^{-\cdot}\right]_{\mathrm{ss}} / \mathrm{M}$ & {$[\mathrm{ORH}] /[\mathrm{ARH}]$} & $10^{4} k_{2} / k_{5}$ \\
\hline tert-Butyl & 10.0 & 3.0 & 60.5 & 60.1 & 38.0 & 1.88 & 3.0 & 0.44 & 0.45 \\
\hline tert-Butyl & 5.0 & 4.1 & 36.3 & 41.3 & 38.0 & 2.00 & 2.5 & 0.24 & 0.67 \\
\hline tert-Butyl & 5.0 & 5.0 & 53.3 & 50.4 & 34.5 & 2.10 & 1.9 & 0.45 & 0.59 \\
\hline tert-Butyl & 5.3 & 4.1 & 71.7 & 80.5 & 38.5 & 1.92 & 1.3 & 0.90 & 0.67 \\
\hline sec-Butyl & 5.0 & 8.0 & 80.9 & 80.3 & 35.0 & 2.01 & 2.2 & 0.12 & 3.0 \\
\hline sec-Butyl & 10.0 & 8.1 & 82.1 & 83.5 & 34.5 & 2.03 & 4.4 & 0.074 & 2.6 \\
\hline sec-Butyl & 10.0 & 2.8 & 52.4 & 60.1 & 36.0 & 2.02 & 6.5 & 0.045 & 2.0 \\
\hline sec-Butyl & 10.0 & 8.2 & 116.0 & 123.0 & 36.5 & 1.99 & 2.9 & 0.27 & 1.6 \\
\hline Butyl & 5.2 & 8.0 & 79.8 & 81.4 & 36.0 & 1.99 & 5.9 & 0.064 & 2.2 \\
\hline Butyl & 5.7 & 4.0 & 84.5 & 80.9 & 34.0 & 1.94 & 6.4 & 0.033 & 3.7 \\
\hline Butyl & 4.0 & 7.9 & 79.8 & 80.6 & 36.0 & 1.94 & 7.9 & 0.039 & 2.6 \\
\hline Butyl & 4.1 & 12.5 & 39.9 & 80.0 & 36.0 & 2.00 & 12.5 & 0.020 & 3.1 \\
\hline
\end{tabular}

Table 9. Rate constant ratio $k_{2} / k_{5}$ for the reaction between $p$-diacetylbenzene radical anion $\left(\mathrm{A}^{-\cdot}\right)$ and alkyl bromides in the presence of ethyl cinnamate from the ratio, [ORH]/[ARH], between addition product to ethyl cinnamate (ORH) and aromatic coupling products $(A R H)$. The number of electrons $n$ is calculated with respect to [A].

\begin{tabular}{|c|c|c|c|c|c|c|c|c|c|}
\hline Alkyl bromide & $-i / \mathrm{mA}$ & {$[\mathrm{A}] / \mathrm{mM}$} & {$[R X] / m M$} & {$[\mathrm{O}] / \mathrm{mM}$} & $\mathrm{V} / \mathrm{ml}$ & $n$ & $10^{5}\left[\mathrm{~A}^{-\cdot}\right]_{\mathrm{ss}} / \mathrm{M}$ & [ORH]/[ARH] & $10^{4} k_{2} / k_{5}$ \\
\hline tert-Butyl & 4.8 & 18.2 & 131 & 83.5 & 34.0 & 0.37 & 1.7 & 0.86 & 0.58 \\
\hline tert-Butyl & 5.0 & 18.1 & 127 & 40.6 & 35.0 & 0.35 & 1.8 & 0.42 & 0.55 \\
\hline tert-Butyl & 4.9 & 16.7 & 121 & 76.8 & 37.0 & 1.02 & 1.7 & 0.60 & 0.75 \\
\hline tert-Butyl & 4.9 & 18.2 & 131 & 41.8 & 34.0 & 0.9 & 1.7 & 0.33 & 0.74 \\
\hline tert-Butyl & 5.0 & 17.7 & 63.9 & 81.1 & 35.0 & 0.84 & 3.5 & 0.34 & 0.68 \\
\hline tert-Butyl & 5.0 & 17.7 & 31.8 & 81.1 & 35.0 & 0.84 & 7.1 & 0.22 & 0.52 \\
\hline sec-Butyl & 5.0 & 17.2 & 61.9 & 78.9 & 36.0 & 0.85 & 3.4 & 0.30 & 1.5 \\
\hline sec-Butyl & 5.0 & 18.8 & 135 & 86.1 & 33.0 & 0.84 & 1.7 & 0.37 & 1.7 \\
\hline sec-Butyl & 5.0 & 19.4 & 69.7 & 88.8 & 32.0 & 0.84 & 3.4 & 0.20 & 1.3 \\
\hline sec-Butyl & 5.0 & 19.4 & 139 & 88.8 & 32.0 & 0.83 & 1.7 & 0.39 & 1.3 \\
\hline sec-Butyl & 5.0 & 18.2 & 131 & 83.5 & 34.0 & 0.84 & 1.7 & 0.36 & 1.4 \\
\hline sec-Butyl & 5.8 & 18.2 & 262 & 83.5 & 34.0 & 0.84 & 0.1 & 0.41 & 2.1 \\
\hline Butyl & 5.0 & 16.3 & 458 & 74.5 & 40.0 & 1.0 & 1.4 & 0.29 & 1.8 \\
\hline Butyl & 5.0 & 19.0 & 362 & 157 & 38.0 & 0.9 & 1.9 & 0.19 & 4.4 \\
\hline Butyl & 5.4 & 15.5 & 344 & 74.5 & 40.0 & 1.0 & 2.0 & 0.14 & 2.6 \\
\hline Butyl & 5.4 & 15.5 & 229 & 74.5 & 40.0 & 1.0 & 3.1 & 0.10 & 2.3 \\
\hline Butyl & 5.2 & 16.3 & 117 & 78.4 & 38.0 & 0.93 & 6.0 & 0.05 & 2.8 \\
\hline Butyl & 5.2 & 16.3 & 117 & 39.2 & 38.0 & 0.93 & 6.0 & 0.04 & 1.7 \\
\hline
\end{tabular}


radicals and thiophenol, the latter being one of the best hydrogen atom donors available. The rate constant for hydrogen abstraction was found to be about $1 \times 10^{8} \mathrm{M}^{-1} \mathrm{~s}^{-1}$; for benzyl radical the rate constant is considerably lower, $3.13 \times 10^{5} \mathrm{M}^{-1} \mathrm{~s}^{-1} .^{23,24}$ The hydrogen atom transfer reaction is so fast that an efficient competition situation can be introduced by adding thiophenol in concentrations in the $\mathrm{mM}$ range.

The standard potential of the thiophenoxide radical has been estimated to be $+0.12 \mathrm{~V}$ vs. SCE in $\mathrm{DMF}^{25}$ which means that almost all aromatic radical anions will immediately be able to reduce this radical to the thiophenolate with full regeneration of the mediator as the result. It should therefore be possible to monitor the transformation from an overall two-electron reduction of the aromatic compound $(q=0)$, when no thiophenol is added, to a full catalytic reduction in the presence of few tenths of a millimole of thiophenol. Two electrons per alkyl halide molecule are consumed and the mediator is regenerated in the fully catalytic case. The choice of mediator is limited by two factors. The standard potential of mediator should be less cathodic than the reduction potential of alkyl radicals $(\approx-1.7 \mathrm{~V}$ vs. SCE) to ensure that no radicals are further reduced by the mediator. On the other hand, the mediator should be selected so that it will reduce the thiophenoxide radical formed. The latter condition requires $E_{\mathrm{A}}^{\circ}$ to be more negative than $-0.2 \mathrm{~V}$ vs. SCE.

The reaction mechanism of the indirect reduction of alkyl halides by aromatic radical ions in the presence of a good hydrogen atom donor is described in eqns. (0)-(3) and (15)-(19). The aliphatic alkyl radical generated in eqn. (1) can either couple with the mediator, $\mathrm{A}^{-\cdot}$, or it can react by hydrogen atom transfer (15) from the added hydrogen atom donor, SH. Eqn. (20) describes the competition between coupling (2) and hydrogen abstraction by the radical (15). The coupling rate constants obtained so far $\left(\approx 1.0 \times 10^{9} \mathrm{M}^{-1} \mathrm{~s}^{-1}\right)$ have been close to the expected diffusion limit in DMF. Only hydrogen abstraction from the most powerful hydrogen atom donors with a high $k_{15}$ will therefore be able to compete successfully with the fast coupling reaction with $\mathrm{A}^{-\cdot}$ and make $\xi_{\mathrm{SH}}$ significant.

$$
\begin{aligned}
& \mathrm{A}+\mathrm{e} \rightleftharpoons \mathrm{A}^{-\cdot} \\
& \mathrm{A}^{-\cdot}+\mathrm{RX} \stackrel{k_{1}}{\longrightarrow} \mathrm{A}+\mathrm{R}^{-}+\mathrm{X}^{-} \\
& \mathrm{A}^{-\cdot}+\mathrm{R} \cdot \stackrel{k_{2}}{\longrightarrow} \mathrm{A}-\mathrm{R}^{-} \\
& \mathrm{A}^{-\cdot}+\mathrm{R} \cdot \stackrel{k_{3}}{\longrightarrow} \mathrm{A}+\mathrm{R}^{-} \\
& \mathrm{SH}+\mathrm{R} \cdot \stackrel{k_{15}}{\longrightarrow} \mathrm{S} \cdot+\mathrm{R}-\mathrm{H} \\
& \mathrm{A}^{-\cdot}+\mathrm{S} \cdot \stackrel{k_{16}}{\longrightarrow} \mathrm{A}-\mathrm{S}^{-} \\
& \mathrm{A}^{-\cdot}+\mathrm{S} \cdot \stackrel{k_{17}}{\longrightarrow} \mathrm{A}+\mathrm{S}^{-}
\end{aligned}
$$

$$
\begin{aligned}
& \mathrm{SH}+\mathrm{AR}^{-} \stackrel{k_{18}}{\longrightarrow} \mathrm{AR}-\mathrm{H}+\mathrm{S}^{-} \\
& \mathrm{S}^{-}+\mathrm{RX} \stackrel{k_{19}}{\longrightarrow} \mathrm{S}-\mathrm{R}+\mathrm{X}^{-} \\
& \xi_{\mathrm{SH}}=\left(\frac{k_{15}}{k_{2}}\right)\left(\frac{[\mathrm{SH}]}{\left[\mathrm{A}^{--}\right]}\right) \\
& \lambda=\left(\frac{R T}{F}\right)\left(\frac{k_{1} C_{\mathrm{A}}^{\circ}}{v}\right)
\end{aligned}
$$

Rate constants, $k_{15}$, found in the literature, for hydrogen atom transfer from thiophenol to some alkyl radicals are collected in Table 11. The values were obtained in THF or DME, but generally they can be assumed to be quite insensitive to changes in solvent. This means that a competition with the coupling reaction can be introduced analytically in LSV with just a few $\mathrm{mM}$ of thiophenol added. For the benzyl radical, $k_{15}$ is significantly smaller and the LSV technique will not be applicable. Thiophenol, besides being a good hydrogen atom donor, is a reasonably good proton donor with $\mathrm{p} K_{\mathrm{a}}=$ 10.7 in DMF and it can protonate most aromatic radical anions. ${ }^{26}$ This side reaction is, however, less important at low thiophenol concentrations and with $p$-dicyanobenzene as mediator. The standard potential of the thiophenoxide radical is about $+0.12 \mathrm{~V}$ vs. SCE in $\mathrm{DMF}^{25}$ as shown in Fig. 2 and therefore almost any aromatic radical anion, and certainly $p$-dicyanobenzene radical anion, will reduce it in eqn. (17) while eqn. (16) can be neglected. The thiophenolate anion may react with primary and secondary alkyl halides in a normal $S_{N} 2$ reaction, but since $[R X]$ is very large compared with $[\mathrm{A}]$ and $[\mathrm{SH}]$ this will not influence the kinetics significantly.

The program Digisim 2.0 was used to simulate the reaction Scheme 3 for LSV. The peak current of the mediator is expected to change from a situation corresponding to two electrons per A, when eqn. (2) predominates over eqn. (15) $\left(\xi_{\mathrm{SH}}=0\right)$, to a two-electron consumption per alkyl halide molecule and a complete regeneration of the mediator when reaction (15) dominates over eqn. (2) $\left(\xi_{\mathrm{SH}} \gg 0\right)$. The reaction scheme was simulated for some ratios of $[\mathrm{RX}] /[\mathrm{A}](10,20,50,100)$, several ratios of $[\mathrm{SH}] /[\mathrm{A}](2,4,8,16,20,40,80,160$, $320)$ and finally for different ratios of $k_{2} / k_{15}(5,10,20$, $30,40,50,100,500)$. The catalytic efficiency $I_{k} / I_{R}$, where

Table 11. Rate constants for hydrogen atom transfer from thiophenol and 2-methyl-2-propanethiol to alkyl radicals at $25^{\circ} \mathrm{C}$.

\begin{tabular}{lll}
\hline Alkyl radical & Hydrogen atom donor & $k_{\mathbf{1 5}} / \mathrm{M}^{-1} \mathrm{~s}^{-1}$ \\
\hline Butyl & Thiophenol & $1.36 \times 10^{8 a}$ \\
Isopropyl & Thiophenol & $1.05 \times 10^{8 a}$ \\
tert-Butyl & Thiophenol & $1.47 \times 10^{8 a}$ \\
Primary radicals & 2-Methyl-2-propanethiol & $8.01 \times 10^{6 b}$ \\
\hline
\end{tabular}

${ }^{a}$ In DME. ${ }^{24}{ }^{b}$ In THF. ${ }^{35}$ 


$$
\begin{aligned}
& \mathrm{A}+\mathrm{e}^{-} \Longrightarrow \mathrm{A}^{-} \\
& \mathrm{RX}\left\{\mathrm{k}_{1}(1)\right. \\
& \mathrm{A}+\mathrm{X}^{-}+\mathrm{R} \cdot \frac{\mathrm{A}^{-}}{\mathrm{k}_{2}} \cdot \mathrm{A}-\mathrm{R} \quad(2) \\
& \mathrm{SH} \backslash \mathrm{k}_{15} \quad(15) \\
& \mathrm{RH}+\mathrm{S}-\frac{\mathrm{A}^{-}}{\mathrm{k}_{17}} \mathrm{~S}^{-}+\mathrm{A}(17)
\end{aligned}
$$

Scheme 3.

$I_{\mathrm{R}}$ is the reversible reduction peak current when only the mediator is present and $I_{\mathbf{k}}$ is the peak current after the alkyl halide and hydrogen atom donor are added, were plotted versus the dimensionless rate constant, $\lambda$, defined in eqn. (21). The simulated working curves for different

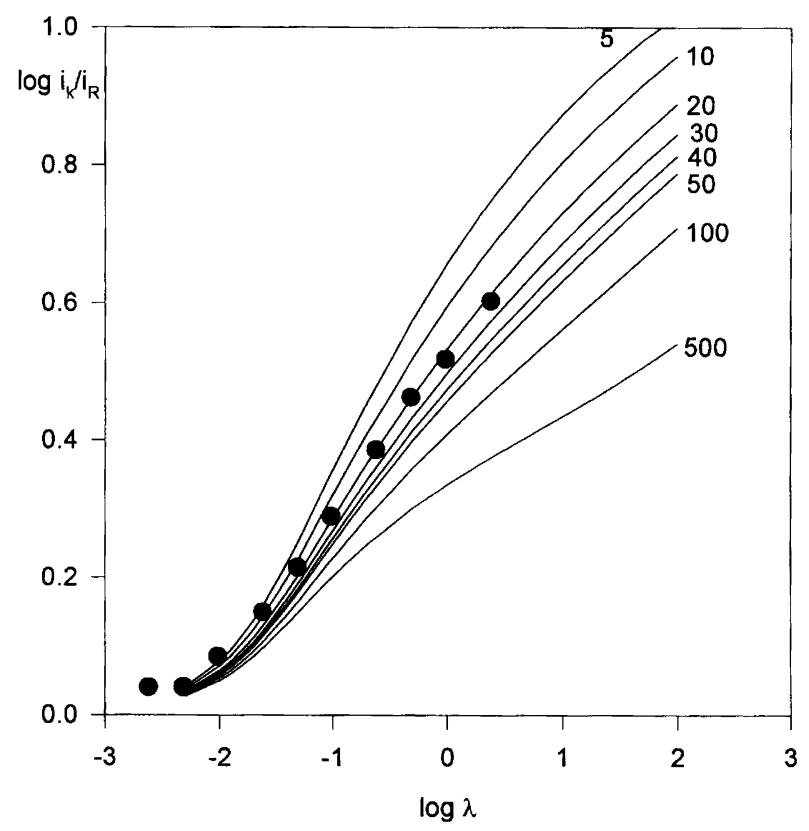

Fig. 6. Simulated curves showing the relationship between the logarithm of the catalytic efficiency $I_{k} / I_{R}$ and the dimensionless rate constant, $\lambda$, for different ratios of $k_{2} / k_{15}$ (legends), for $[\mathrm{RX}] /[\mathrm{A}]=10$ and $[\mathrm{SH}] /[\mathrm{A}]=4$. The experimental points included in the figure are for $2 \mathrm{mM}$ of $p$-dicyanobenzene, $20 \mathrm{mM}$ of isopropyl iodide and $8 \mathrm{mM}$ of thiophenol in DMF-0.1 M Bu $\mathrm{NBF}_{4}$ at $25^{\circ} \mathrm{C}$. ratios of $k_{2} / k_{15}$ are shown in Fig. 6 together with the experimental values for the reaction between $p$-dicyanobenzene radical anion and isopropyl iodide in the presence of thiophenol. The experimental points are seen to fit reasonably well to the simulated curve with $k_{2} / k_{15}$ equal to 20. It was thus possible to calculate $k_{2}$ using the values of $k_{15}$ given in Table 11. The results are included in Table 12 together with similar results for butyl, isopropyl and tert-butyl radicals and $p$-dicyanobenzene radical anion, and for butyl radical and benzophenone radical anion. For the butyl radical it was possible to use both thiophenol and 2-methyl-2-propanethiol as the hydrogen atom donor even though the latter is around 15 times less efficient a hydrogen donor than thiophenol, and larger excesses of the thiol were necessary. On the other hand, 2-methyl-2-propanethiol, with a $\mathrm{p} K_{\mathrm{a}}$ value of about $17,{ }^{26}$ is a much weaker proton donor than thiophenol and it can therefore be tolerated in higher concentrations without the aromatic radical anion being protonated.

The coupling rate constants given in Table 12 range from $1 \times 10^{9}$ to $2.8 \times 10^{9} \mathrm{M}^{-1} \mathrm{~s}^{-1}$. A tendency in these results is that the rates of coupling of alkyl radicals with aromatic radical anions are in the order primary $>$ secondary $>$ tertiary but the differences are still so small that the trend might be an artefact. The same trend was not observed for the coupling rate constants obtained in the addition experiments. The results are probably not influenced by the presence of a competing $\mathrm{S}_{\mathrm{N}} 2$ reaction between $\mathrm{A}^{-\cdot}$ and $\mathrm{RX}$, since this reaction path is unlikely when alkyl iodides are used as substrates. It seems general that normal, secondary and tertiary radicals couple with aromatic radical anions with approximately the same rate constant that is quite close to the diffusion-controlled limit. Two radicals are, in fact, expected to couple very fast and the activation barrier is very small. A consequence of this low activation energy is that electronic effects on the SOMO-SOMO interaction are expected to play almost no role. Therefore we do not see the same trends as in radical addition to olefins where the rate constant is highly influenced by the SOMO-LUMO interaction. In Ref. 11 it was found that aromatic radical anions with very different standard potentials $\left(\Delta E_{\mathrm{A}}^{\circ}=0.9 \mathrm{~V}=88 \mathrm{~kJ} \mathrm{~mol}^{-1}\right)$ (SOMO energies) coupled with primary radicals with approximately the same rate constant. This trend is confirmed by the fact that even a difference in standard potentials between $p$ -

\begin{tabular}{|c|c|c|c|c|}
\hline Alkyl radical & H-donor & [H-donor]/[A] & $k_{2} / k_{15}$ & $10^{-9} k_{2} / \mathrm{M}^{-1} \mathrm{~s}^{-1}$ \\
\hline Butyl & Thiophenol & $2,4,8,16$ & 20 & 2.8 \\
\hline Butyl & 2-Methyl-2-propanethiol & $20,40,80,160,320$ & 300 & 2.4 \\
\hline Butyl (benzophenone) & 2-Methyl-2-propanethiol & 10,20 & 200 & 1.6 \\
\hline Isopropyl & Thiophenol & $2,4,8,16$ & 20 & 2.0 \\
\hline tert-Butyl & Thiophenol & $2,4,8$ & 10 & 1.0 \\
\hline
\end{tabular}
diacetylbenzene and anthracene of $0.5 \mathrm{~V}\left(48 \mathrm{~kJ} \mathrm{~mol}^{-1}\right)$ results in only a minor change of $k_{2}$ from 1.5 to

Table 12. LSV results from indirect reduction of alkyl iodides by p-dicyanobenzene (and benzophenone) in the presence of $\mathrm{H}$-atom donors in DMF-0.1 M TBABF 4 . 
$0.9 \times 10^{9} \mathrm{M}^{-1} \mathrm{~s}^{-1}$. The difference in steric hindrance between a tert-butyl radical or a butyl radical is also seen to play no significant role in the coupling reaction. This is expected because the approach to the aromatic radical anion can proceed unhindered from both sides of the flat or fast flexing molecule. In fact, even two tertbutyl radicals are found to couple in the gas-phase only three times slower that two ethyl radicals. ${ }^{27}$

It could be of synthetic interest to be able to generate alkyl radicals by indirect reduction of alkyl halides to initiate radical reactions such as olefin additions. However, mediators have to be found that will not undergo fast coupling with the alkyl radicals generated. Recent results have indicated that the triphenylmethyl radical does not, or only slowly, couple with aromatic radical anions.

Savéant et al. recently studied the electrochemical initiation of substitution of 1-iodoadamantane by arenethiolate ions. ${ }^{28}$ It was found that the coupling reaction between the adamantyl radical and anthracene radical anion was too fast to allow any reaction with the thiolate nucleophile ( $k_{2}$ around $10^{9}-10^{10} \mathrm{M}^{-1} \mathrm{~s}^{-1}$ ). When 9,10diphenylanthracene was used as a mediator a small amount of substitution product could be obtained but even in this case $k_{2}$ was estimated to be around $10^{9}$. It is difficult to imagine that this coupling rate constant will be lower for other combinations of alkyl radical and aromatic mediator affecting less steric hindrance.

Finally we make some comments about the assumptions and limitations of the two methods used here. In the first method based on the intermolecular addition of alkyl radicals to activated olefins, the following assumptions were made: (1) $k_{1}[\mathrm{RX}]<0.1 \mathrm{~s}^{-1}$; (2) $k_{2} \gg k_{3}$; (3) $k_{2}\left[\mathrm{~A}^{-\cdot}\right] \approx k_{5}[\mathrm{O}]$, and finally (4) $k_{6} \ll k_{7} \approx k_{\text {diff. }}$. The first limitation is included to insure that the concentration of $\mathrm{A}^{-\cdot}$ is homogeneous during the preparative electrolysis. The half-life of $\mathrm{A}^{-\cdot}$ of around $7 \mathrm{~s}$ is sufficiently high to allow complete mixing in the cathodic compartment. If only aromatic compounds with standard potentials higher than the reduction potentials for the alkyl radicals are used then the coupling reaction (2) will be much faster than the ET reaction (3) and the second limitation will be fulfilled. Reduction potentials for many radicals are known to be lower than $-2.1 \mathrm{~V}$ vs. SCE (except for the methyl radical with $E_{\mathrm{R}}=-1.78 \mathrm{~V}$ vs. $\mathrm{SCE}$ ) and this restricts the method to aromatic compounds with $E_{\mathrm{A}}^{\circ}>-2.10 \mathrm{~V}$ vs. SCE. The third assumption, being the basic idea of this method, can be tuned by the concentration ratio $[\mathrm{O}] /\left[\mathrm{A}^{-\cdot}\right]$ or by the rate constant ratio $k_{5} / k_{2}$. The latter ratio is generally $10^{-3}-10^{-4}$ for activated olefins and therefore the concentration ratio needs to be high. There is a risk that very activated olefins when present in high concentrations will react directly with the aromatic radical anion as was observed with fluoranthene and acrylonitrile. The last assumption, 4, that the formed radical, $\mathrm{OR}$, should be reduced by $\mathrm{A}^{-\cdot}$, eqn. (7), almost at a diffusion-controlled rate is found when $E_{\mathrm{A}}^{\circ}$ is lower than the reduction potential for $\mathrm{OR}$. If the latter is benzylic, as found when $\mathrm{O}$ is styrene, then $E_{\mathrm{A}}^{\circ}<-1.45 \mathrm{~V}$ vs. SCE should be a sufficient condition to drive eqn. (7) at the diffusioncontrolled limit $\left(k_{7} \approx 10^{10} \mathrm{M}^{-1} \mathrm{~s}^{-1}\right)$. If aromatic compounds with $E_{\mathrm{A}}^{\circ}>-1.45 \mathrm{~V}$ vs. SCE are considered then the product analysis is further complicated because HA-OR coupling products now have to be quantified. Furthermore there is a risk of $\mathrm{OR}$ reacting with the olefin and polymerising when the lifetime of $\mathrm{OR}$ is approximately ten times higher because $k_{6} / k_{7} \approx 0.1$.

The second method using the LSV technique is also restricted by a number of assumptions and limitations: (1) $k_{1}>1000 \mathrm{M}^{-1} \mathrm{~s}^{-1}$; (2) $k_{2} \gg k_{3}$; (3) $k_{2}\left[\mathrm{~A}^{-\cdot}\right]$ $\approx k_{15}[\mathrm{SH}] ;$ (4) $k_{17} \gg k_{16}$, and finally (5) $k_{1}[\mathrm{RX}]$ $\gg k_{\mathrm{H}^{+}}[\mathrm{SH}]$. The rate-determining step, the ET reaction between $\mathrm{A}^{-\cdot}$ and $\mathrm{RX}$ has to be fast so the voltammogram will be completely irreversible and the peak current at low scan rate should be almost doubled as an indication of purely kinetic control. Restriction 2 is the same as the corresponding one in the first method. The third assumption, that is the basic idea of this method, can be tuned by the concentration ratio $[\mathrm{SH}] /\left[\mathrm{A}^{-\cdot}\right]$ or by the rate constant ratio $k_{15} / k_{2}$. The latter ratio for thiophenol is 0.1 , but for other hydrogen atom donors this ratio is much lower and the concentration ratio $[\mathrm{SH}] /\left[\mathrm{A}^{-\cdot}\right]$ needs therefore to be higher to compensate for these less efficient hydrogen atom donors. In LSV, where the concentration of $\mathrm{A}$ is normally fixed to $1-2 \mathrm{mM}$, much higher concentrations of $\mathrm{SH}$ are needed when $\mathrm{SH}$ is a less potent hydrogen atom donor. The fourth limitation is the least demanding because all aromatic compounds with $E_{\mathrm{A}}^{\circ}<-0.2 \mathrm{~V}$ vs. SCE will transfer an electron to $\mathrm{S}^{\circ}$ under diffusion control and therefore nearly all aromatic compounds will reduce $S \cdot$ at a rate that is almost diffusion-controlled. The last restriction is very important since most efficient hydrogen atom donors are also quite efficient proton donors $\left(\mathrm{p} K_{\mathrm{a}}=10.7\right.$ for thiophenol in DMF) and they can protonate most aromatic radical anions. In this application, however, a low concentration of thiophenol is needed and the radical anion of $p$-dicyanobenzene is less liable to be protonated than are other aromatic radical anions.

It should be clear from this summary of the assumptions and restrictions for the two methods that careful design of the experiments is necessary and none of these methods is sufficiently general that coupling rate constants for a long list of aromatic radical anions and alkyl radicals can be measured.

\section{Conclusions}

Radical addition to activated olefins and hydrogen atom transfer reaction to radicals can compete with the fast coupling reaction between alkyl radicals and aromatic radical anions, but only under the most favourable conditions. The addition reaction was favoured over the coupling reaction by decreasing the rate of the latter by decreasing the steady-state concentration of the aromatic 
Table 13. Collection of rate constants for coupling of alkyl radicals and aromatic radical anions measured by different methods in DMF-0.1 M Bu $\mathrm{MBF}_{4}$ at $25^{\circ} \mathrm{C}$.

\begin{tabular}{|c|c|c|c|}
\hline Alkyl radical & Aromatic radical anion & $10^{-9} k_{2} / \mathrm{M}^{-1} \mathrm{~s}^{-1}$ & Method $^{a}$ \\
\hline tert-Butyl & Anthracene & 0.8 & ATO \\
\hline tert-Butyl & $p$-Diacetylbenzene & 1.7 & ATO \\
\hline tert-Butyl & $p$-Dicyanobenzene & 1.0 & HAT \\
\hline sec-Butyl & Anthracene & 1.0 & ATO \\
\hline sec-Butyl & $p$-Diacetylbenzene & 1.3 & ATO \\
\hline Isopropy| & p-Dicyanobenzene & 2.0 & HAT \\
\hline Butyl & Anthracene & 0.9 & ATO \\
\hline Butyl & $p$-Diacetylbenzene & 2.0 & ATO \\
\hline Butyl & p-Dicyanobenzene & 2.6 & HAT \\
\hline Butyl & Benzophenone & 1.6 & HAT \\
\hline Hex-5-enyl & Quinoxaline & $3.5^{b}$ & RCY \\
\hline 2,2-Dimethylhex-5-enyl & Benzophenone & $0.5^{b}$ & RCY \\
\hline 2,2-Dimethylhex-5-enyl & Anthracene & $1.4^{b}$ & RCY \\
\hline
\end{tabular}

${ }^{a}$ Methods abbreviations: addition to olefin (ATO), hydrogen atom transfer (HAT), radical cyclisation probe (RCY). ${ }^{b}$ From Ref. 11.

radical anion $\left[\mathrm{A}^{-\cdot}\right]_{\mathrm{ss}}$. The hydrogen atom transfer reactions are, for some special donors, thiophenol, 2-methyl-2-propanethiol and tributyltin hydride, much faster than the radical addition reactions to olefins. This means that the hydrogen atom transfer reactions can compete with the coupling reaction even when the concentration of the aromatic radical anions is in the $\mathrm{mM}$ range, thus allowing this competition to be analysed by standard electroanalytical techniques.

The results from this and previous studies with electrogenerated aromatic radical anions are collected in Table 13. Three points can be concluded: (a) the coupling reaction between alkyl radicals and aromatic radical anions is fast with rate constants approaching the diffusion limit, which reflects the lack of significant activation barriers; (b) the small activation energy involved in the coupling reactions results in insensitivity to structural differences in the alkyl radical and in the aromatic radical anion and (c) the coupling reaction is relatively insensitive to variations in SOMO-SOMO interactions. Aromatic radical anions with large differences $\left(0.9 \mathrm{~V}\right.$ or $\left.88 \mathrm{~kJ} \mathrm{~mol}^{-1}\right)$ in standard potentials and SOMO energies are seen to couple with the alkyl radical with approximately the same rate constant. ${ }^{9,11}$ Again this is a consequence of the low activation barrier.

It has previously been assumed that all alkyl, benzyl and acyl radicals react with aromatic radical anions with rate constants of around $1 \times 10^{9} \mathrm{M}^{-1} \mathrm{~s}^{-1}$. Now experimental results support this assumption for different alkyl radicals and a number of aromatic radical anions; however measurements are still needed before the assumption for benzyl and acyl radicals can be verified. The results here show that the coupling reaction can be used as an intermolecular radical clock to obtain rate constants for the ET reaction (3) between the alkyl radical and the aromatic radical anion. If Marcus theory is used then these rate constants, $k_{3}$, can be used to estimate standard potentials for alkyl radicals.

\section{Experimental}

Materials. The mediators anthracene, $p$-diacetylbenzene and $p$-dicyanobenzene were the same as used previously ${ }^{29}$ and are commercially available. The butyl bromides were all obtained from Aldrich and were purified further by distillation when necessary. The alkyl iodides were commercially available and distilled prior to use and stored over copper pieces. Thiophenol (Aldrich) and 2-methyl-2-propanethiol (Aldrich) were distilled and checked by GC to be of $>99 \%$ purity and less than $0.5 \%$ disulfide. 9-Butyl-9,10-dihydroanthracene and 9-isobutyl-9,10-dihydroanthracene were synthesised according to Harvey and Cho. ${ }^{30}$ 1-Phenylhexane was prepared by Friedel-Craft acylation of benzene by hexanoyl chloride followed by catalytic hydrogenation. 1-Phenyl-3,3-dimethylbutane was synthesised according to the literature procedure. ${ }^{31}$

The supporting electrolyte tetrabutylammonium tetrafluoborate, $\mathrm{Bu}_{4} \mathrm{NBF}_{4}$, was synthesised using the procedure described in Ref. 6. DMF was obtained from Aczo. The electrolyte solution $\mathrm{DMF}-0.1 \mathrm{M} \mathrm{Bu} \mathrm{NBF}_{4}$ was dried through a column of activated alumina before use.

Equipment. The concentration of $\mathrm{A}^{-\cdot}$ was monitored with a fibre-optic spectrometer (S1000) from Ocean Optics Inc. equipped with a transmission dip probe with light pathlength of either 10 or $2 \mathrm{~mm}$. The gratings in the spectrometer allowed measurements from 250 to $750 \mathrm{~nm}$. A tungsten-halogen lamp was used as the light source. A home-made low-current $(<20 \mathrm{~mA})$ galvanostat was used in the electrolysis. The instrumentation and cells for cyclic voltammetry and linear sweep voltammetry have been described previously. ${ }^{32}$ The working electrode was a glassy carbon $\operatorname{rod}(\phi=1 \mathrm{~mm})$ melted into glass under vacuum. The reference electrode was a Pyrex glass tube $(\phi=7 \mathrm{~mm})$ closed at one end by a porous ceramic material (TZ) from Export Technishe Keramik, München. A silver wire ( $\phi=1 \mathrm{~mm})$ was inserted into the 
tube and a solution of $\mathrm{DMF}-0.1 \mathrm{M} \mathrm{Bu}_{4} \mathrm{NBF}_{4}-0.01 \mathrm{M}$ $\mathrm{Bu}_{4} \mathrm{NI}$ was added.

Products were identified by GC-MS carried out on a Hewlett Packard 5890 A gas chromatograph equipped with a 5971A MSD. An HP5 $25 \mathrm{~m}, 0.25 \mathrm{~mm}$ internal diameter GC-column was used, injection temperature $250^{\circ} \mathrm{C}$, helium flow $1.0 \mathrm{ml} \mathrm{min}^{-1}$, temperature program $100^{\circ} \mathrm{C}$ for $2 \mathrm{~min}$ to $300^{\circ} \mathrm{C}$, rate $10^{\circ} \mathrm{C} \mathrm{min}^{-1}$. Quantitative analyses were performed by GC-FID. The ${ }^{1} \mathrm{H}$ NMR spectra were recorded with a Bruker $250 \mathrm{MHz}$ or a Varian Gemini $200 \mathrm{MHz}$ spectrometer.

Methods. Olefin addition experiments. An $\mathrm{H}$-cell with a $25 \mathrm{ml}$ cathodic compartment was filled with DMF-0.1 M $\mathrm{Bu}_{4} \mathrm{NBF}_{4}$. The working electrode was a platinum net $\left(16 \mathrm{~cm}^{2}\right)$ and the anode was a carbon rod. The dip probe was installed in the cathodic compartment through a rubber stopper at the top just like a normal reference electrode. The cathodic compartment was flushed with argon and stirred magnetically. All experiments were carried out at room temperature $\left(25^{\circ} \mathrm{C}\right)$.

Visible spectra of anthracene or p-diacetylbenzene radical anion were obtained in $2 \mathrm{mM}$ solutions of the aromatic compound in the cathodic compartment. The galvanostatic current was adjusted to $10 \mathrm{~mA}$ and held there for 1-2 min. Visible spectra from 400 to $750 \mathrm{~nm}$ could be recorded continuously with the tungsten-halogen lamp by means of the dip probe, and $\lambda_{\max }$ could be determined. The spectrometer software (SpectraScope) was then adjusted so only the absorption at $\lambda_{\max }$ was recorded continuously and the corresponding extinction coefficient could be calculated from the slope of absorbance vs. time.

Kinetic and steady-state measurements. The $\mathrm{H}$-cell was filled with 4-10 mM anthracene or $p$-diacetylbenzene and alkyl halide in a tenfold excess. The galvanostatic current was adjusted to $5.0 \mathrm{~mA}$ and after a short while the steady-state absorption was recorded at the $\lambda_{\max }$ for $\mathrm{A}^{-}$. by the spectrometer. The same procedure was carried out at currents equal to 10.0 and $20.0 \mathrm{~mA}$. The absorption due to $\mathrm{A}^{-\cdot}$ followed an exponential decay when the galvanostat was switched off. A plot of $\ln A$ vs. time gave the pseudo-first-order rate constant, $k_{1}^{\prime}=2 k_{1}[\mathrm{RX}]$. The kinetic and steady-state measurements were performed three times before and after the addition of the olefin.

Preparative method with anthracene and styrene. In a typical experiment $0.145 \mathrm{mmol}$ of anthracene, $2.87 \mathrm{mmol}$ of 1-chlorobutane, $2.90 \mathrm{mmol}$ of styrene and $0.385 \mathrm{mmol}$ of tetradecane (GC internal standard) were added to the cathodic compartment. A constant current was adjusted to $7.0 \mathrm{~mA}$; a faint blue colour was noted. The total charge consumed was $27.12 \mathrm{C}$ before the experiment was stopped. The volume of the solution in the cathodic compartment was measured $(36 \mathrm{ml})$, then $10 \mathrm{ml}$ of water were added, and the solution was extracted three times with $40 \mathrm{ml}$ of diethyl ether. The ether solution was washed three times with $20 \mathrm{ml}$ of water and dried overnight with molecular sieves ( $4 \AA$ ). Finally the solvent was evaporated off and the sample analysed by GC and GC-MS.

Preparative method with $\mathrm{p}$-diacetylbenzene and ethyl cinnamate. In a typical experiment $p$-diacetylbenzene ( $0.62 \mathrm{mmol})$, ethyl cinnamate $(2.98 \mathrm{mmol})$ and tert-butyl bromide $(4.46 \mathrm{mmol})$ were reduced at constant current $(5 \mathrm{~mA})$ at a platinum net electrode in an $\mathrm{H}$-cell containing a cathodic volume of $35 \mathrm{ml}$ of an argon-deaerated solution of DMF-0.1 M tetrabutylammonium tetrafluoborate $\left(\mathrm{TBABF}_{4}\right)$. After the consumption of $50 \mathrm{C}$ two drops of acetic acid were added, together with diphenyl as an internal standard and the electrolysis mixture analysed by GC-FID (Scheme 4).<smiles>[R]C1c2ccccc2C([2H])c2ccccc21</smiles>

1 a-c<smiles>[R]CCc1ccccc1</smiles><smiles>[R]C(C)(O)c1ccc(C(C)=O)cc1</smiles>

3 a-c

R:<smiles>CCCCC</smiles>

b: $-\mathrm{CH}\left(\mathrm{CH}_{3}\right) \mathrm{CH}_{2} \mathrm{CH}_{3}$

c: $-\mathrm{C}\left(\mathrm{CH}_{3}\right)_{3}$
Scheme 4.

Identification of compounds. p-Diacetylbenzene + tertbutyl bromide (ARH): 2-(4-Acetylphenyl)-3,3dimethyl-2-butanol (3c). ${ }^{1} \mathrm{H}$ NMR $\left(\mathrm{CDCl}_{3}\right): \delta 0.86(\mathrm{~s}$, $9 \mathrm{H}), 1.55(\mathrm{~s}, 3 \mathrm{H}), 2.51(\mathrm{~s}, 3 \mathrm{H}), 7.47(\mathrm{~d}, 2 \mathrm{H}, J=$ $6.7 \mathrm{~Hz}), 7.78(\mathrm{~d}, 2 \mathrm{H}, J=6.7 \mathrm{~Hz})$. MS [m/z (\%)]: $205(3)$, 165 (9), 164 (89), 163 (100), 121 (22), 147 (7), 43 (74). p-Diacetylbenzene + sec-butyl bromide (ARH): 2-(4-Acetylphenyl)-3-methyl-2-pentanol (diastereoisomeric mixture) (3b). ${ }^{1} \mathrm{H}$ NMR $\left(\mathrm{CDCl}_{3}\right): \delta$ 0.94-1.1 (m, $6 \mathrm{H}), 1.3-1.8(\mathrm{~m}, 6 \mathrm{H}), 1.48+1.51(\mathrm{~s}, 3 \mathrm{H}), 2.52(\mathrm{~s}$, $3 \mathrm{H}$ ), 7.48 (d, $2 \mathrm{H}, J=8.5 \mathrm{~Hz}), 7.84$ (d, $2 \mathrm{H}, J=8.5 \mathrm{~Hz}$ ). GC-MS showed two lines of same intesity and with identical mass spectra $[\mathrm{m} / \mathrm{z}(\%)]: 205(3), 165(9), 164$ (89), 163 (100), 121 (22), 147 (7), 43 (74).

p-Diacetylbenzene + butyl bromide (ARH): 2-(4Acetylphenyl)-2-hexanol (3a). ${ }^{1} \mathrm{H}$ NMR $\left(\mathrm{CDCl}_{3}\right): \delta$ 0.86-1.4 (m,7 H), $1.50(\mathrm{~s}, 3 \mathrm{H}), 1.75(\mathrm{t}, 2 \mathrm{H}), 2.54(\mathrm{~s}$, $3 \mathrm{H}), 7.49$ (d, $2 \mathrm{H}, J=8.2 \mathrm{~Hz}), 7.87(\mathrm{~d}, 2 \mathrm{H}, J=8.2 \mathrm{~Hz})$. MS [m/z (\%)]: $205(3), 165(9), 164(89), 163(100), 121$ (22), 147 (7), 43 (74).

p-Diacetylbenzene + tert-butyl bromide +ethyl cinna- 
mate (ORH): Ethyl 3,3-dimethyl-2-(phenylmethyl)butanoate (4c). MS [m/z (\%)]: 234 (6), 178 (13), 177 (100), 149 (14), 131 (68), 105 (17), 91 (76), 65 (13), 57 (21). The spectrum is identical with previously published data. ${ }^{33}$

p-Diacetylbenzene + sec-butyl bromide+ethyl cinnamate (ORH): Ethyl 3-methyl-2-(phenylmethyl)pentanoate (4b). MS [m/z (\%)]: 234 (13), $178(16), 177$ (79), 160 (19), 149 (13), 131 (79), 105 (12), 104 (14), $91(100)$.

p-Diacetylbenzene + butyl bromide+ethyl cinnamate (ORH): Ethyl 2-(phenylmethyl) hexanoate (4a). MS [m/z (\%)]: 234 (13), 178 (16), 177 (79), 160 (19), 149 (13), 131 (79), 105 (12), 104 (14), 91 (100).

Direct $C V$ with olefin or hydrogen atom donor added. The $\mathrm{CV}$ and LSV experiments followed standard procedures. $^{32,34}$ The LSV experiments were repeated three times with a waiting time between successive experiment corresponding to ten times the total scan time. The current was for each LSV experiment measured at discrete scan rates $\left(50,100,200 \ldots 10000 \mathrm{mV} \mathrm{s}^{-1}\right)$.

Cyclic voltammetry was used to investigate the protonation of the aromatic radical anions with thiophenol and 2-methyl-2-propanethiol in order to ensure that this process would not be in competition with reaction (1). The basicity of the radical anion of $p$-dicyanobenzene was found to be so low that both thiols could be employed without further considerations, but in the case of benzophenone radical anion the protonation rate was much higher especially with thiophenol and the experiments could only be carried out with 2-methyl-2-propylthiol in the presence of a large excess of alkyl halide.

\section{References}

1. Lund, H., Daasbjerg, K., Occhialini, D. and Pedersen, S. U. Russ. J. Electrochem. 31 (1995) 865.

2. Wayner, D. D. M., McPhee, D. J. and Griller, D. J. Am. Chem. Soc. 110 (1988) 132.

3. Lund, H. and Simonet, J. J. Electroanal. Chem. 65 (1975) 205.

4. Daasbjerg, K., Pedersen, S. U. and Lund, H. Acta Chem Scand. 43 (1989) 876.

5. Daasbjerg, K., Pedersen, S. U. and Lund, H. Acta Chem Scand. 45 (1991) 424.

6. Lund, T. and Lund, H. Acta Chem Scand., Ser. B 40 (1986) 470.
7. Garst, J. F. and Barton, F. E. Tetrahedron Lett. 7 (1969) 587.

8. Garst, J. F. and Smith, C. D. J. Am. Chem. Soc. 98 (1976) 1520.

9. Garst, J. Acc. Chem. Res. 4 (1971) 400.

10. Chatgilialoglu, C., Ingold, K. U. and Scaiano, J. C. J. Am. Chem. Soc. 103 (1981) 7739

11. Pedersen, S. U. and Lund, T. Acta Chem Scand. 45 (1991) 397.

12. Zhou, D.-L., Walder, P., Scheffold, R. and Walder, L. Helv. Chim. Acta 75 (1992) 995.

13. Levy, M. and Szwarc, M. J. Am. Chem. Soc. 82 (1960) 521.

14. Mengoli, G. and Vidotto, G. Makromol. Chem. 129 (1969) 73 .

15. Bhugun, I. and Savéant, J.-M. J. Electroanal. Chem. 408 (1996) 5

16. Kharasch, M. S. and Sage, M. J. Org. Chem. 14 (1949) 537.

17. Holm, T., Crossland, I. and Madsen, J. Ø. Acta Chem. Scand., Ser. B 32 (1978) 754.

18. Héberger, K., Walbiner, M. and Fischer, H. Angew. Chem. 104 (1992) 651.

19. Münger, K. and Fischer, H. Int. J. Chem. Kinet. 17 (1985) 809.

20. Andrieux, C. P., Gallardo, I., Savéant, J.-M. and Su, K.-B. J. Am. Chem. Soc. 108 (1986) 638.

21. Sørensen, H. S. and Daasbjerg, K. Acta Chem. Scand. 52 (1998) 51.

22. Giese, B. Angew. Chem. 95 (1983) 771.

23. Franz, J. A., Suleman, N. and Alnajjar, M. S. J. Org. Chem. 51 (1986) 19.

24. Franz, J. A., Bushaw, B. A. and Alnajjar, M. S. J. Am. Chem. Soc. 111 (1989) 268.

25. Christensen, T. B. and Daasbjerg, K. Acta Chem. Scand. 51 (1997) 307.

26. Izutsu, K., Ed., Acid-Base Dissociation Constants in Dipolar Aprotic Solvents, Chemical Data Series, Vol. 35, Blackwell, London 1990.

27. Parkes, D. A. and Quinn, C. P. J. Chem. Soc., Faraday Trans. 1 (1976) 1952.

28. Ahbala, M., Hapiot, P., Houmam, A., Jouini, M., Pinson, J. and Saveant, J.-M. J. Am. Chem. Soc. 117 (1995) 11488.

29. Daasbjerg, K. and Lund, H. Acta Chem. Scand. 47 (1993) 597.

30. Harvey, R. G. and Cho, H. J. Am. Chem. Soc. 96 (1974) 2435.

31. Ohno, M., Shimizu, K., Ishizaki, K., Sasaki, T. and Eguchi, S. J. Org. Chem. 53 (1988) 729.

32. Gatti, N., Pedersen, S. U. and Lund, H. Acta Chem. Scand., Ser. B 42 (1988) 1.

33. Jalander, L. Acta Chem. Scand., Ser. B 35 (1981) 419.

34. Bard, A. J. and Faulkner, L. R. Electrochemical Methods, Fundamentals and Applications, Wiley, New York 1980.

35. Newcomb, M., Glenn, A. G. and Manek, M. B. J. Org. Chem. 54 (1989) 4603.

Received April 17, 1997. 